\title{
Scenario Forecasting for Global Tourism
}

Doris chenguang Wu, Zheng Cao, long Wen, Haiyan

Song

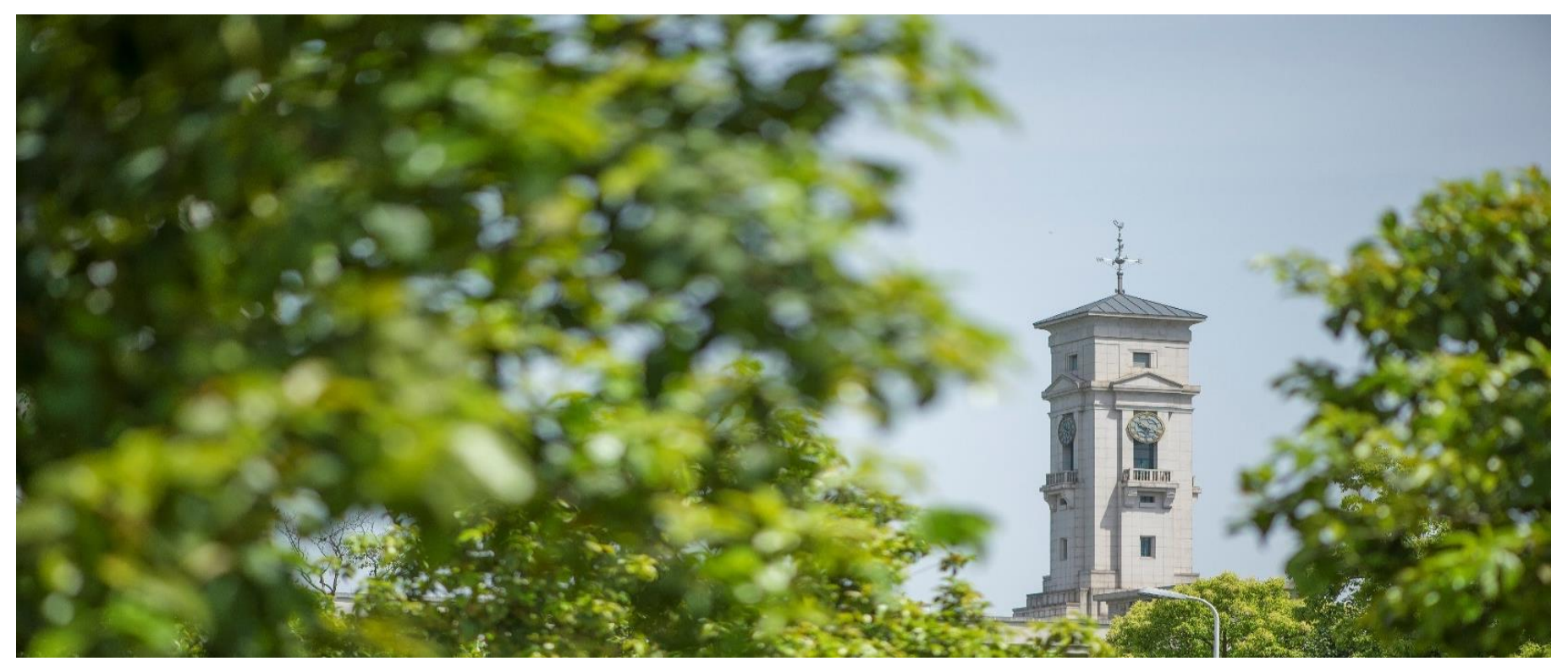


Faculty of Humanities and Social Science, University of Nottingham Ningbo China, 199 Taikang East Road, Ningbo, 315100, Zhejiang, China.

First published 2020

This work is made available under the terms of the Creative Commons Attribution 4.0 International License:

http://creativecommons.org/licenses/by/4.0

The work is licenced to the University of Nottingham Ningbo China under the Global University Publication Licence:

https://www.nottingham.edu.cn/en/library/documents/researchsupport/global-university-publications-licence-2.0.pdf 


\title{
Scenario Forecasting for Global Tourism
}

\begin{abstract}
This study provides innovative forecasts of the probabilities of certain scenarios of tourism demand. The scenarios of interest are constructed in relation to tourism growth and economic growth. The probability forecasts based on these scenarios provide valuable information for destination policymakers. The time-varying parameter panel vector autoregressive (TVPPVAR) model is adopted for scenario forecasting. Both the accuracy rate and the Brier score are used to evaluate the forecasting performance. A global set of 25 tourism destinations is empirically examined, and the results confirm that the TVP-PVAR model with a timevarying error covariance matrix is generally a promising tool for forecasting. Our study contributes to tourism forecasting literature in advocating the use of scenario forecasting to facilitate industry decision-making in situations wherein forecasts are defined by two or more dimensions simultaneously. In addition, it is the first study to introduce the TVP-PVAR model to tourism demand forecasting.
\end{abstract}

Keywords: scenario forecasting, time-varying parameter panel vector autoregressive, tourism growth, economic growth, Brier score 


\section{INTRODUCTION}

Forecasting tourism demand is vital to tourism business planning and policy making and has received increasing attention from industry practitioners in recent years ( $\mathrm{Li} \& \mathrm{Wu}, 2019)$. The current practice of tourism demand forecasting is dominated by point forecasting $(\mathrm{Wu}$, Song, \& Shen, 2017), which often provides an expected average outcome for future development; however, tourism demand is susceptible to volatile market conditions, and relevant stakeholders may need various types of forecasts to make better informed decisions (Hall, 2010; Lewis \& Pain, 2015; Ringbeck \& Pietsch, 2013). It is, therefore, increasingly important to understand the degree of variability or uncertainty that surrounds point forecasts (Greenwood-Nimmo, Nguyen, \& Shin, 2012). To this end, interval forecasting is desirable because it predicts a likely range of future outcomes, thus allowing for contingency planning (Christoffersen, 1998). Interval forecasting has been applied in tourism and hospitality studies, such as those by Athanasopoulos, Hyndman, Song, and Wu (2011), Kim, Song, and Wong (2010), Kim, Wong, Athanasopoulos, and Liu (2011), and Li, Wu, Zhou, and Liu (2019). Interval forecasts provide a range of outcomes instead of a single point of forecasting for future tourism demand at a preset confidence level/probability (Li et al., 2019).

Although interval forecasts are considered to be an effective supplement to point forecasts because they provide information about the degree of variability or uncertainty of the forecasts ( $\mathrm{Li}$ et al., 2019), they cannot describe the predicted likelihood of predefined outcomes in which decision makers are interested. In reality, industry practitioners and policymakers may be concerned about certain scenarios that are closely related to their objectives and operation strategies (e.g., if the future inflation rate falls within the $2 \%-5 \%$ interval) and may therefore need forecasts regarding the possibilities of these scenarios to plan ahead and achieve optimal results. Scenario forecasting allows forecasters to specify the threshold values that define events of interest so that the probability of the specified events 
can be generated accordingly. Even more importantly, scenario forecasting allows an event of interest to be defined on the basis of the values of more than one variable simultaneously, such as a joint event of tourism growth acceleration and gross domestic product (GDP) growth deceleration. This enables researchers and practitioners to construct complicated scenarios with multiple dimensions. As such, scenario forecasting is a promising tool for tourism researchers to explore any range of outcomes in relation to future tourism demand (e.g., gauging the possibility of a recession in tourism demand) and investigate the policy implications of those outcomes.

Thus, this study extends the current tourism forecasting literature by conducting probabilistic forecasting of global tourism demand in various scenarios. Four scenarios are developed to jointly consider the variables of tourism growth and economic growth. These two variables are adopted for scenario construction because the information they provide is important to market practitioners, and they correlate and interact with each other in an economic system. The values of the predicted probabilities of the scenarios provide insights into the degree of confidence/risk associated with different decisions. With the inclusion of these two variables, the following four scenarios can be generated: tourism growth acceleration and economic growth acceleration, tourism growth acceleration and economic growth deceleration, tourism growth deceleration and economic growth acceleration, and tourism growth deceleration and economic growth deceleration. The events of interest are based on various rates of tourism growth and economic growth. We identify an effective approach to obtaining an accurate probability using a theoretically sound modeling technique - time-varying parameter panel vector autoregressive (TVP-PVAR) modeling. The study's results will provide policymakers and tourism businesses with an outlook regarding the potential developments in major tourism markets while accounting for various uncertainties. 
The significance of this study is threefold. First, it introduces probabilistic scenario forecasting to the tourism literature as an effective supplement to point or interval forecasts when policymakers and industry practitioners are interested in the probability of a certain scenario happening. Second, from a methodological perspective, scenarios that jointly consider more than one variable are generated, and a suitable hybrid model - the TVP-PVAR model — is applied and examined accordingly. The PVAR model is an effective approach to capturing the cross-sectional effects in one system and is therefore most suitable to our scenario setting, whereas the TVP technique enhances forecasting accuracy performance owing to its time-varying features and empirical evidence. Therefore, this hybrid model is expected to achieve good forecasting performance. Third, unlike the traditional TVP model, both the coefficients and the covariance matrix of errors are allowed to vary over time in the TVP settings of this study, and the constant-coefficient models and the TVP models with different time-varying settings are examined separately. This sheds new light on the application of the TVP model in tourism forecasting.

This study is organized as follows. The following literature review section discusses relevant studies on tourism forecasting and scenario forecasting. The methods section presents discussions of the PVAR model, TVP-PVAR model, performance evaluation of scenario forecasting, scenario setting, and data. The empirical results section reports and compares the forecasting performance of the various models. The last concluding remarks section concludes the study and suggests directions for future research.

\section{LITERATURE REVIEW}

\section{Tourism demand forecasting}

Demand modeling and forecasting represent a prime area of tourism research. It has undergone remarkable developments since the 1990s, especially in terms of advances in research methods. 
As widely reviewed (Song \& Li, 2008; Wu et al., 2017), statistical methods of tourism demand forecasting generally fall into three broad categories, as follows. (1) Non-causal time series methods, such as exponential smoothing models (e.g., double exponential smoothing and Holt-Winters exponential smoothing), autoregressive moving average models (e.g., autoregressive integrated moving average and seasonal autoregressive integrated moving average), and structural time series models, some of which are often used as benchmark models for accuracy comparison. (2) Econometric methods, such as error correction models, autoregressive distributed lag models, vector autoregressive models, and almost-ideal demand system (AIDS) models. (3) Artificial intelligence-based methods, such as the artificial neural network model, support vector regression, the rough set model, and fuzzy system methods.

Econometric methods have an advantage over other methods in capturing the causal relationships between tourism demand and a wide range of determinants (Song, Qiu, \& Park, 2019). These methods allow businesses and policymakers to formulate strategies and policies that target certain determinants. A recent development in econometric methods is the global vector autoregressive (GVAR) model (Pesaran, Schuermann, \& Weiner, 2004), which can account for the endogeneity within a large set of cross-sectionally interdependent variables while overcoming the overparameterization issue or "curse of dimensionality" (Bussière, Chudik, \& Sestieri, 2009). This model has been applied in macroeconomic forecasting (e.g., Favero, 2013; Greenwood-Nimmo et al., 2012; Pesaran, Schuermann, \& Smith, 2009). In the context of tourism research, the GVAR model presents opportunities to study the global interdependence of tourism markets, in which countries share a certain level of co-movement with respect to their macroeconomic characteristics and tourism demand (Assaf, Li, Song, \& Tsionas, 2019; Cao et al., 2017). Another highly relevant development in econometric methods is the PVAR model, which allows multiple variables to be treated as endogenous 
simultaneously. This model can also be effectively used with a relatively short time-series dimension because of the efficiency gained from the cross-sectional dimension that allows the inclusion of fixed effects to capture time-invariant components (Grossmann, Love, \& Orlov, 2014; Lof \& Malinen, 2014). In view of the popularity of the Bayesian approach in the VAR literature, Canova and Ciccarelli (2004) introduced the Bayesian version of the PVAR model and showed that their approach is competitive and improves on existing univariate and simple Bayesian VAR models. In the field of tourism research, Mahadevan and Suardi (2019) applied the PVAR model to measure the effects of tourism growth on poverty reduction. Still, the PVAR model has room for wider use.

A recurrent limitation of econometric models is predictive failure, which is normally associated with the structural instability of the model; that is, the parameters of the demand model vary over time (Song, Witt, \& Li, 2009, p. 138). One reason for structural instability is the underlying structural change in the data-generating process, which may be related to important social, political, and economic changes (Song, Witt, \& Li, 2009, p. 138). To account for underlying changes embedded in the data, the time-varying parameter (TVP) model, a non-linear modeling technique, has been applied in tourism research. To assess the effects of the global economic crisis and swine flu pandemic on the demand for U.K. tourism, Page, Song, and Wu (2012) constructed a TVP model to yield ex post forecasts of demand under no-impact and economic-impact scenarios and estimated the effects of the events by comparing the two scenarios. The TVP model is also used in combination with other models to achieve superior performance. Li, Song, and Witt (2006) developed a TVP error correction AIDS model that outperforms its fixed-parameter counterparts in the overall evaluation of demand forecasts.

In view of the TVP model's advantages, Koop and Korobilis (2019) developed the TVP-PVAR model and demonstrated its superiority to alternative methods for large vector 
autoregressions in the context of forecasting inflation rates in the eurozone. However, applications of this model in tourism research are lacking.

\section{Scenario forecasting}

Scenario forecasting can be divided into two main types. In the first type, tourism demand is forecast given certain conditions/scenarios, such as optimisticor pessimistic scenarios. For example, Page et al. (2012) separated the impacts of swine flu pandemic and economic crisis on the demand for U.K. tourism by forecasting tourism demand under two scenarios: a noimpact scenario and an economic crisis impact scenario. This type of scenario forecasting still belongs to the scope of point forecasting. The second type of scenario forecasting involves the prediction of the probability of a given scenario/condition, and it belongs to the scope of probabilistic forecasting. This study focuses on the second type of scenario forecasting, i.e., probabilistic scenario forecasting.

A point forecast can be fairly accurate if the data correspond to a period of stability, but it alone cannot convey the degree of variability or uncertainty, which has been increasingly recognized as important information by academics and practitioners (Garratt, Lee, Pesaran, \& Shin, 2003; Greenwood-Nimmo et al., 2012). To mitigate this limitation of point forecasts, one can use interval forecasts, which generates forecasting intervals given a preset confidence level/probability. Interval forecasts have two advantages over single forecasts (Li et al., 2019): (i) they provide information on both the central tendency of the forecast and the future variation at a certain confidence level, and (ii) they can generate different forecast intervals based on different confidence levels preset by the forecasters, which helps with policy and strategy formulation based on those confidence levels.

In addition to the advantages provided by point and interval forecasts, probabilistic scenario forecasting can offer supplemental information from a new perspective by generating the probability that a predefined outcome happens. Thus, probabilistic scenario 
forecasting may be particularly useful when the decision makers are interested in the possibility of a certain scenario happening in the future. Scenario forecasting has three main advantages. First, forecasters can decide the scope of the event to be forecast by specifying the threshold values that define an event of interest. Second, scenario forecasting allows an event of interest to be defined based on the values of two or more variables simultaneously, in which a joint event can be defined, and compute its possibility. This enables researchers and practitioners to construct complicated scenarios with multiple dimensions. Third, the results of scenario forecasting are very straightforward and are more likely to be understood and adopted by decision makers.

Closely related to scenario forecasting, scenario planning has been adopted as a research framework in the field of tourism (e.g., Moriarty, 2012; Page et al., 2010). It argues that nothing in the future is certain or predictable, especially in view of the growing recognition that global tourism is operating in turbulent times. Global issues such as climate change, the use of oil as a fuel, and terrorism inevitably create great uncertainties for the tourism sector (Page et al., 2010). As such, credible sense-making can be achieved using ranges of scenarios that encompass possible extrema that conceivably and traceably arise from the current operating environment (Moriarty, 2012). Although scenario planning is considered important, scenario forecasting, as the foundation for scenario planning, has received less attention from academics and deserves further examination under different scenario forecasting settings.

\section{Scenario settings}

This study aims to examine the performance of scenario forecasting using a theoretically sound forecasting method, in which a two-dimensional scenario is developed that jointly considers tourism growth and economic growth at the destination. These two variables are chosen for scenario settings for three reasons. First, tourism growth and economic growth are 
both important indicators for decision-making by market practitioners, and a large body of empirical research has verified that these two variables are highly correlated (e.g., Brida, Cortes-Jimenez, \& Pulina, 2016; Liu \& Wu, 2019; Nunkoo et al., 2019; Wu et al., 2019). Therefore, compared with the examination of two variables independently and separately, scenario settings based on these two variables can capture their interaction effects and provide industry practitioners with more comprehensive information on the tourism market. This finding is also consistent with that of van Doorn (1986), who stated that tourism development and its outside societal influences should be embedded within a scenario.

Second, comparing the growth rates of the two variables provides important information for strategy formulation and resource allocation at the destination. For example, it may be wise to invest in tourism rather than another industry when the scenario of tourism demand acceleration and economic growth deceleration is forecast to happen with the highest probability, but not when this scenario is forecast with the lowest probability.

Third, in scenario forecasting that considers both economic growth and tourism growth, the values of the predicted probabilities provide practitioners with the level of risk associated with each decision. For example, it is less risky to invest aggressively in the tourism industry if the scenario of tourism demand acceleration and economic growth acceleration is forecast with a high probability, such as $90 \%$. However, the risk associated with this decision will increase when this scenario is forecast to have a lower probability.

For the abovementioned reasons, the scenarios examined in this study are set considering both economic growth and tourism growth. In particular, four scenarios are considered for scenario forecasting: tourism growth acceleration and economic growth acceleration, tourism growth acceleration and economic growth deceleration, tourism growth deceleration and economic growth acceleration, and tourism growth deceleration and economic growth deceleration. 
Given the volatile market conditions faced by the tourism sector worldwide, scenario forecasting is an appealing tool for tourism researchers to explore possibilities in relation to future tourism demand and economic growth and investigate the policy implications of such outcomes. This is the first study to provide scenario forecasts that consider both worldwide tourism demand and economic growth, and its findings will enrich the tourism forecasting research field and provide the industry with new insights into the complex global tourism system.

\section{METHODS}

\section{The PVAR model}

With the increase in globalization, economic activities in various countries have become more interconnected. Correspondingly, efforts to accommodate and model such links have also increased. Various model specifications have been proposed and used in previous studies, including the GVAR model (Dees, Mauro, Pesaran, \& Smith, 2007) and the multi-country PVAR model (Canova \& Ciccarelli, 2009). Cao et al. (2017) were the first to apply the GVAR model in the tourism context, and Assaf et al. (2019) further used its Bayesian version. This study is the first to use the PVAR model to model cross-unit interdependencies for tourism demand forecasting. The PVAR model is constructed by augmenting VAR models for each individual country with lagged dependent variables from other countries. The specification of the PVAR model for each country $(i=1, \ldots, N)$ with $p$ lags can be written as

$$
y_{i t}=A_{i}^{1} Y_{t-1}+\cdots+A_{i}^{p} Y_{t-p}+u_{i t}
$$

where $\boldsymbol{y}_{i \boldsymbol{t}}$ is the $G \times 1$ vector of dependent variables for country $i$ at time $t(t=1, \ldots, T) ; \boldsymbol{Y}_{\boldsymbol{t}}=$ $\left(y_{1 t}^{\prime}, \ldots, y_{N t}^{\prime}\right)^{\prime}$ is the $N G \times 1$ vector of dependent variables for $N$ countries; $\boldsymbol{A}_{\boldsymbol{i}}^{j}$ is the $G \times N G$ matrix of the PVAR coefficients for country $i$ and lag $j$; and $\boldsymbol{u}_{i t}$ is the $G \times 1$ vector of disturbances, $\boldsymbol{u}_{i t} \sim N\left(0, \Sigma_{i i}\right)$, which are not correlated over time but may be correlated across countries. We denote $E\left(\boldsymbol{u}_{i t} \boldsymbol{u}_{j t}\right)=\Sigma_{i j}$ and $\Sigma$ as the $N G \times N G$ error covariance matrix for 
$u_{t}=\left(\boldsymbol{u}_{1 t}^{\prime}, \ldots, \boldsymbol{u}_{\boldsymbol{N} t}^{\prime}\right)^{\prime}$. For notational simplicity, an intercept is not added, and this omission does not affect the illustration of the model specifications. An intercept is included in the empirical work of this study.

An unrestricted PVAR model has $K=p \times(N \times G)^{2}$ unknown autoregressive parameters to be estimated, which is likely to cause over-parameterization. To solve this problem, Canova and Ciccarelli (2009) suggested the use of a factor structure for the PVAR coefficients. If we define $A_{j}=\left(A_{1}^{j}, \ldots, A_{N}^{j}\right)$ for $j=1, \ldots, p$ and $\alpha=\left(\operatorname{vec}\left(\mathrm{A}^{1}\right)^{\prime}, \ldots, \operatorname{vec}\left(\mathrm{A}^{P}\right)^{\prime}\right)^{\prime}$, then $\alpha$ is assumed to follow the factor structure

$$
\alpha=\Xi_{1} \theta_{1}+\Xi_{2} \theta_{2}+\cdots+\Xi_{\mathbf{q}} \theta_{\mathbf{q}}+\mathbf{e}=\Xi \theta+\mathbf{e}
$$

where $\Xi=\left(\Xi_{1}, \ldots, \Xi_{\mathrm{q}}\right)$ is known and decided based on the assumed factor structure and $\theta=$ $\left(\theta_{1}^{\prime}, \ldots, \theta_{q}^{\prime}\right)^{\prime}$ is an $R \times 1$ vector of unknown parameters with $R$ being much smaller than $K$. e is assumed to not be correlated with $u_{t}$ and has a normal distribution with mean 0 and covariance matrix $\Sigma \otimes V$, where $V=\sigma^{2} I$. The factor structure used by Canova and Ciccarelli (2009) suggests that $\alpha$ consists of three types of factors: a common factor, a factor specific to each country, and a factor specific to each variable. Under this setting, $q=3 . \Xi_{1}$ is a $K \times 1$ vector of ones, and $\theta_{1}$ is a scalar that represents the common factor. $\Xi_{2}$ is a $K \times$ $N$ matrix that comprises zeroes and ones to select coefficients for each country, and $\theta_{2}$ is an $N \times 1$ vector that represents country-specific factors. $\Xi_{3}$ is a $K \times G$ matrix that comprises zeroes and ones to select coefficients for each variable, and $\theta_{3}$ is an $G \times 1$ vector that represents variable-specific factors. By imposing factor structure restriction, the dimensions of the parameters decrease greatly from $K$ in $\alpha$ to $R=1+N+G$ in $\theta_{1}, \theta_{2}$, and $\theta_{3}$. This strategy is used to estimate the PVAR model in this study. 


\section{The TVP-PVAR model}

The assumption of constant parameters can occasionally be too restrictive, but it can be relaxed using the TVP method. By adding the subscript $t$ to $\alpha$, the TVP-PVAR model can be written in the matrix form as

$$
Y_{t}=X_{t}^{\prime} \alpha_{t}+u_{t}
$$

where $\mathrm{X}_{t}=I \otimes\left(\mathrm{Y}_{t-1}^{\prime}, \ldots, \mathrm{Y}_{t-p}^{\prime}\right)^{\prime}$ and $\boldsymbol{\alpha}_{\boldsymbol{t}}$ follows a random walk process. However, as noted above, this form can lead to over-parameterization if no restriction is imposed. Therefore, as an extension of the model used by Canova and Ciccarelli (2009), Koop and Korobilis (2019) proposed a time-varying version that assumes a random walk of the factors

$$
\begin{aligned}
& \boldsymbol{\alpha}_{\boldsymbol{t}}=\boldsymbol{\Xi} \boldsymbol{\theta}_{\boldsymbol{t}}+\mathbf{e}, \\
& \theta_{t}=\theta_{t-1}+w_{t},
\end{aligned}
$$

where $\theta_{t}$ is an $R \times 1$ vector of unknown parameters, which changes following a random walk process, and $w_{t} \sim N\left(0, W_{t}\right)$, where $W_{t}$ is an $R \times R$ covariance matrix. The TVP-PVAR model can then be rewritten in a state space form as

$$
\begin{aligned}
& \boldsymbol{Y}_{\boldsymbol{t}}=\widetilde{\boldsymbol{X}}_{\boldsymbol{t}}^{\prime} \boldsymbol{\theta}_{\boldsymbol{t}}+\boldsymbol{v}_{\boldsymbol{t}}, \\
& \theta_{t}=\theta_{t-1}+w_{t},
\end{aligned}
$$

where $\tilde{X}_{t}=X_{t} \boldsymbol{\Xi}$ and $\boldsymbol{v}_{\boldsymbol{t}}=\tilde{X}_{t}^{\prime} \mathrm{e}+u_{t}$ with $v_{t} \sim N\left(0,\left(I+\sigma^{2} X_{t}^{\prime} X_{t}\right) \times \Sigma\right)$. Equation (6) is the measurement equation, and Equation (7) is the state equation. Following Canova and Ciccarelli (2009), $\sigma^{2}$ is set as 0 in this study. If $W_{t}$ is known, the Kalman filter can be applied to estimate $\theta_{t}$. A Bayesian analysis, given the priors of $W_{t}$,would entail the use of Markov chain Monte Carlo methods to generate the posterior distribution for $\theta_{t}$; however, this approach would create a heavy computational burden and could be prohibitive in some cases. An alternative approach with forgetting factors is commonly used to estimate state space models such as the TVP-PVAR model. Detailed discussions can be found in studies by Dangl and Halling (2012) and Raftery et al. (2010). The motivation to use forgetting factors 
is to avoid the need to estimate or simulate $W_{t}$. To illustrate this point, if we denote $D_{t-1}$ as the data available until time $t-1$, then the only place that involves $W_{t}$ in the Kalman filter iteration is

$$
\operatorname{var}\left(\theta_{t} \mid D_{t-1}\right)=\operatorname{var}\left(\theta_{t-1} \mid D_{t-1}\right)+\widehat{W}_{t}
$$

If we replace this equation with

$$
\operatorname{var}\left(\theta_{t} \mid D_{t-1}\right)=\frac{1}{\lambda} \operatorname{var}\left(\theta_{t-1} \mid D_{t-1}\right)
$$

$W_{t}$ no longer plays a role in the Kalman filtering process. $\lambda$ is the forgetting factor with a range of $0<\lambda \leq 1$ and is often set to a number slightly less than 1 (Raftery et al., 2010). Equations (8) and (9) imply that

$$
\widehat{W}_{t}=\left(\frac{1}{\lambda}-1\right) \operatorname{var}\left(\theta_{t-1} \mid D_{t-1}\right)
$$

and it can be seen that $W_{t}=0$ when $\lambda=1$, which suggests constant parameters. Using the forgetting factor approach can greatly reduce the computational burden, so it is adopted in this study.

The TVP-PVAR model can be further extended to allow the error covariance to vary by time; that is, $v_{\boldsymbol{t}} \sim N\left(0, \Sigma_{t}\right)$. Exponentially weighted moving average methods are used in this study to estimate $\Sigma_{t}$ :

$$
\widehat{\boldsymbol{\Sigma}}_{t}=\kappa \widehat{\boldsymbol{\Sigma}}_{t-1}+(\mathbf{1}-\kappa) \widehat{\boldsymbol{u}}_{t} \widehat{\boldsymbol{u}}_{t}^{\prime}
$$

where $\widehat{\boldsymbol{u}}_{\boldsymbol{t}} \widehat{\boldsymbol{u}}_{\boldsymbol{t}}^{\prime}=\left(Y_{t}-\tilde{X}_{t}^{\prime} E\left(\theta_{t} \mid D_{t-1}\right)\right)\left(Y_{t}-\tilde{X}_{t}^{\prime} E\left(\theta_{t} \mid D_{t-1}\right)\right)^{\prime}$ and $0<\kappa \leq 1$. $\kappa$ is the decay factor. Following the version introduced by Koop and Korobilis (2019), a relatively diffuse choice of an initial value of $0.1 \times I$ is set for $\widehat{\Sigma}_{t}$.

The forgetting factor $\lambda$ and the decay factor $\kappa$ determine the levels of time variation of $\theta_{t}$ and $\hat{\Sigma}_{t}$,respectively. Higher values of $\lambda$ and $\kappa$ suggest faster changes over time. When $\lambda=\kappa=1, \theta_{t}$ and $\hat{\Sigma}_{t}$ become time invariant, and the resulting PVAR model has constant parameters and is homoscedastic. In this study, to investigate the effects of time variation in 
the parameters and error covariance on the forecasting performance of the PVAR model, we use $\lambda=0.9$ and $\kappa=0.9$. As in the studies by Canova and Ciccarelli (2009) and Koop and Korobilis (2019), the maximum lag $p$ in this study is set to 1 for the PVAR model.

As we are interested in generating scenario forecasts that depend on the values of the corresponding variables in the past four periods, the forecasts at horizon $h>1$ depend on the forecasts at earlier steps. Therefore, forecast simulations are performed to calculate the probability of scenario forecasts in this study, and the number of simulations is set to 500 .

\section{Scenario forecasting evaluation}

As this study's focus is scenario forecasting, both the accuracy rate and the Brier score are used as the evaluation metrics. The accuracy rate is defined as the percentage of correct predictions, i.e., the fraction of instances that are correctly classified, as shown below:

$$
\mathrm{AR}=\frac{C P}{M}
$$

where $A R$ is the accuracy rate, $M$ is the number of forecasts in the test period, and $C P$ is the number of correct predictions. Here, "correct predictions" refers to the situation in which the scenario with the highest probability in scenario forecasting occurs in reality. Therefore, higher accuracy rates indicate better forecasts.

In addition to examining whether the scenario with the highest probability occurs in reality, the Brier score includes the probability values for each scenario in the evaluation of the accuracy of scenario forecasting. The Brier score, proposed by Brier in 1950, is commonly used to evaluate forecasts that assign probabilities to a set of mutually exclusive discrete outcomes. It is a proper scoring rule that encourages the forecaster to make careful assessments and be honest. The importance of being proper has been widely recognized (Bröcker \& Smith, 2007). The Brier score for multiclass forecasts can be defined as 


$$
\mathrm{BS}=\frac{1}{M} \sum_{t=1}^{M} \sum_{i=1}^{C}\left(F_{t i}-A_{t i}\right)^{2}
$$

where $F_{t i}$ is the forecast probability assigned to class $i$ at forecast period $t, A_{t i}$ is the actual outcome for class $i$ at forecast period $t$ ( 0 if it does not occur and 1 if it does), $M$ is the number of forecasting periods, and $C$ is the number of possible classes (i.e., four in this study). The Brier score measures the mean squared difference between the predicted probabilities and the actual outcomes; therefore, it can take values between 0 and 1 . A lower Brier score indicates better scenario forecasts.

\section{Scenario setting and data processing}

As discussed in the literature review, the scenarios examined in this study are set considering both economic growth and tourism growth for the following three reasons. These two variables always reflect practitioners' interests and are correlated; scenario forecasting using these two variables provides valuable information for decision-making; and the predicted probabilities provide insights into the degrees of risk associated with different decisions. In particular, economic growth is measured by GDP growth at the destination. Referring to tourism growth, according to the literature, tourism demand is often measured by tourist arrivals (such as Wang 2009) and tourism expenditure (such as Wang 2014). These variables measure tourism demand from different perspectives. According to the IMF (2009), tourism exports are related to the goods and services acquired from an economy by visiting nonresidents, either for their own use or to give away. Therefore, tourism exports are indeed comparable with tourism expenditure as a measure of tourism demand, as the core component of both is the spending of tourists at the destination. The tourism exports indicator has also been adopted in several previous studies, e.g., those by Gray (1966), Artus (1972), Smeral and Witt (1996), Smeral and Weber (2000), and Smeral (2004). Therefore, this study uses tourism export growth as the measure of tourism growth. 
Therefore, the scenarios of interest in this study are related to a country's tourism export growth and economic growth. Specifically, we devise the following four scenarios for each country:

Scenario 1: Economic growth accelerates, and tourism growth accelerates.

Scenario 2: Economic growth decelerates, and tourism growth accelerates.

Scenario 3: Economic growth decelerates, and tourism growth decelerates.

Scenario 4: Economic growth accelerates, and tourism growth decelerates.

Growth acceleration has attracted considerable research attention since the 2000s (e.g., Hausmann, Pritchett, \& Rodrik, 2005; Jong-A-Pin \& De Haan, 2011). In the tourism literature, economic growth and tourism growth have been used to construct scenarios (Smeral and Weber, 2000). Empirical evidence has shown that cyclical fluctuations in GDP and tourism income have different lengths and that tourism income has greater volatility than the GDP cycle (Eeckels, Filis, \& Leon, 2012).

Hence, the four scenarios identified above follow the existing literature on the cyclical patterns in the tourism sector and the wider economy. In particular, scenarios 2 and 4 justify the need for a specific level of support for the tourism sector compared with the rest of the economy, given the cyclical pattern of tourism exports. Although both tourism exports and imports can be incorporated into a scenario, we focus on tourism exports because this indicator (i.e., inbound tourism) has a far more direct influence on, and thus greater relevance to, local economic growth than tourism imports.

Growth acceleration represents a speeding up of growth rate, i.e., when economic growth rate at period $t$ is higher than that in previous periods. In economics literature, it is defined based on $\Delta g_{t}\left(g_{t}\right.$ represents the economic growth rate at $t$ ) (e.g., Greenwood-Nimmo, Nguyen, \&Shin, 2012; Hausmann, Pritchett, \& Rodrik, 2005; Stankov, 2018), although the specific operational definition may vary across studies. 
In this study, we follow Greenwood-Nimmo, Nguyen, and Shin (2012) in operationally defining acceleration as the case in which the growth rate of the target variable at quarter $t$ is higher than the average of its growth rates in the previous four quarters:

$$
\Delta \ln y_{i, t} \geq\left(\Delta \ln y_{i, t-1}+\Delta \ln y_{i, t-2}+\Delta \ln y_{i, t-3}+\Delta \ln y_{i, t-4}\right) / 4
$$

where $\ln y_{i, t}$ refers to the natural logarithm of tourism exports (or GDP) for the $i$ th country at quarter $t$ and $\Delta$ is the difference operator.

Deceleration is defined as occurring when the growth rate of the target variable at quarter $t$ is lower than the average of its growth rates in the previous four quarters:

$$
\Delta \ln y_{i, t}<\left(\Delta \ln y_{i, t-1}+\Delta \ln y_{i, t-2}+\Delta \ln y_{i, t-3}+\Delta \ln y_{i, t-4}\right) / 4
$$

In total, four endogenous variables are included in the system modeling process: economic growth, tourism price, real tourism imports, and real tourism exports. Economic growth is measured by the natural logarithm of the GDP index for each country, and tourism price is measured by the exchange rate-adjusted consumer price index (CPI):

$P_{i, t}=C P I_{i, t} / E X_{i, t}$

where $P_{i, t}, C P I_{i, t}$, and $E X_{i, t}$ are the tourism price, CPI, and exchange rate for the $i$ th country at quarter $t$, respectively. Real tourism exports are measured by the tourism priceadjusted total tourism exports:

$$
\operatorname{export}_{i, t}^{\text {real }}=\operatorname{export}_{i, t} / P_{i, t},
$$

where export $_{i, t}^{\text {real }}$ denotes real tourism exports and export $_{i, t}$ denotes total tourism exports. Real tourism imports are measured by total tourism imports adjusted by the weighted tourism price:

$$
\text { import }_{i, t}^{\text {real }}=\text { import }_{i, t} / \sum_{j=1}^{24} w_{j, i, t} P_{j, t},
$$


where import ireal $_{i, t}$ denotes real tourism imports, import $_{i, t}$ denotes total tourism imports, and $w_{j, i, t}$ is the share of country $j$ 's trade weight among country $i$ 's total trading partners at quarter $t$, which is calculated using a $25 \times 25$ matrix with the elements representing the average of the absolute values of imports and exports. The matrix changes every year, and the matrices for 1993 to 2016 are constructed accordingly.

The data are seasonally adjusted using the X-13 method and transformed into the natural logarithm format before establishing the model. We use data for 1993Q1 to 2016Q4 from 25 major economies worldwide: Australia, Belgium, Brazil, Canada, China, France, Germany, India, Italy, Japan, Korea, Mexico, Netherlands, New Zealand, Norway, the Philippines, Portugal, Singapore, Slovenia, South Africa, Spain, Sweden, Thailand, the U.K., and the U.S.. As shown in Table 1, the data are obtained from open sources, such as the IMF's International Financial Statistics and Balance of Payments Statistics databases and the economies' respective national statistics offices.

--------Insert Table 1 here---------

\section{EMPIRICAL RESULTS}

Table 2 shows the accuracy rates for the 25 countries over 8 forecasting horizons. A higher accuracy rate refers to more accurate forecasting. Random choice is a benchmark that assigns each scenario equal probability, with an accuracy rate of 0.25 . The first observation is that the accuracy rates of the best models (in bold font) for all scenarios are greater than 0.25 , which indicates that the forecasting techniques can improve the scenario forecasting accuracy. It can also be observed that although the best model varies by country and by the forecasting horizon, the average accuracy rates (the last column in Table 2) indicate that the TVP-PVAR model generally performs best when the error variances are time-varying [either $\operatorname{TVP}(\lambda)$ - 
PVAR or TVP $(\lambda \kappa)$-PVAR] for most forecasting horizons, with two exceptions ( $h=5$ and 7$)$ in which the VAR(2) model performs best. This observation supports the application of the TVP-PVAR model with time-varying error variances for scenario forecasting. It can further be observed from Table 2 that the accuracy decreases when the forecasting horizon increases, which is consistent with most findings in the forecasting literature. However, even for the horizon of 8 , the forecasting accuracy of each model is superior to random choice on average.

--------Insert Table 2 here--------

Table 3 shows the Brier scores of the 25 countries for forecasting evaluation. A lower Brier score indicates better forecasting performance. The average Brier scores (the last column in Table 3) indicate that the TVP-PVAR models outperform the benchmark of the VAR models for all horizons. The best model is the TVP $(\kappa)$-PVAR model for six horizons $(h=1,2, \ldots, 6)$, and the TVP $(\lambda \kappa)$-PVAR model for two horizons ( $h=7$ and 8$)$. On average, the TVP-PVAR models with a time-varying error covariance matrix generate the most accurate scenario forecasts. This conclusion is consistent with the results of accuracy rates.

--------Insert Table 3 here--------

When the Brier scores of all 25 countries are examined in Table 3, it can be seen that the TVP-PVAR model is more advantageous for forecasting horizons within 1 year $(h=1,2,3$, and 4) than over 2 years $(h=5,6,7$, and 8). In particular, the TVP $(\kappa)$-PVAR model produces the most accurate forecasts for $h=1,2$, and 4: the TVP( $\kappa)$-PVAR model is the best model in 11 of the 25 cases for one-step-ahead forecasting, in 12 of the 25 cases for two-step-ahead forecasting, and in 9 of the 25 cases for four-step-ahead forecasting. When $h=3$, both the 
$\operatorname{TVP}(\kappa)$-PVAR model and the TVP $(\lambda \kappa)$-PVAR model perform best (both in 9 of the 25 cases). Therefore, we conclude that the TVP-PVAR model with a time-varying covariance matrix of errors is the optimal approach to the scenario forecasting of global tourism and economic growth when short-run forecasting (i.e., within 1 year) is required.

When longer forecasting horizons are examined, the TVP $(\lambda \kappa)$-PVAR model generally performs best. When $h=5$, both the TVP( $\lambda \kappa)$-PVAR model and VAR(2) perform best in 9 of the 25 cases. When $h=7$, the TVP $(\lambda \kappa)$-PVAR model, the TVP( $\kappa)$-PVAR model, and the VAR(2) model show similar performance, with each performing best in 7 of the 25 cases. When $h=8$, the TVP $(\lambda \kappa)$-PVAR model performs best in 7 of the 25 cases. For $h=6$, the VAR(2) model performs best in 8 of the 25 cases; this is the only instance in which the TVPPVAR models fail to outperform the benchmark model. In other words, for $h=6$, when considering the average Brier scores of the 25 countries, the TVP $(\lambda \kappa)$-PVAR model is the best choice (see Table 3). However, when considering the accuracy rates (see Table 2) or the times in which the model performs best, based on the Brier scores of the 25 countries (see Table 3), the VAR(2) model is the best choice.

In conclusion, we examine scenario forecasting using the TVP-PVAR model and use accuracy rates and Brier scores to evaluate the forecasting performance. The TVP-PVAR models generally outperform the benchmark models in most cases, which supports our assumption. Furthermore, the TVP-PVAR model that considers the time-varying error covariance matrix is especially effective for short-run forecasting (i.e., within 1 year). This finding not only theoretically enriches the tourism forecasting literature but also provides practical guidance for achieving accurate scenario forecasting using a system model.

\section{CONCLUDING REMARKS}

Unlike traditional demand forecasting, which predicts the volume of tourism demand, such as tourist arrivals or tourism receipts, this study innovatively forecasts events and/or scenarios 
of tourism demand. The scenarios for forecasting could be constructed based on a single event or by jointly considering more than one event. Scenario forecasts provide information on the possibility that a given event or scenario will occur in reality. Accordingly, practitioners can gain knowledge of the reliability of and risks associated with decisions about certain strategies and policies. When more than one event is used for scenario construction, three factors should be considered: these events should be of interest to market practitioners or scholars; they should be related; and the constructed scenarios or new events should be of interest to market practitioners or scholars.

As stated in the above discussion regarding scenario construction, this study generates scenarios based on two important variables: tourism exports and economic growth at a given destination. A total of 25 destination countries are examined simultaneously in a system model (i.e., the PVAR model) in which the interactions of these 25 destinations can be well captured. In particular, the TVP version of the PVAR model is used, and the constantparameter PVAR and VAR models are used as benchmarks. Eight forecasting horizons are examined separately, and the accuracy rates and Brier scores are used to evaluate the predicted probability.

The empirical results reveal interesting findings. First, the TVP-PVAR model with a time-varying error covariance matrix generally performs better than the benchmark models in forecasting the probability of a given scenario or event over 8 forecasting horizons and 25 destinations. This finding suggests that the proposed model is a promising tool for forecasting. Second, our study shows that it is important to allow the error covariance matrix to vary over time in the TVP settings. This aspect is often omitted in forecasting studies. Finally, this study shows that in addition to accuracy rates, which are often used to evaluate classification accuracy, Brier scores can be used to measure the accuracy of scenario forecasting because the predicted probability is included for evaluation. 
This study makes important contributions to the tourism forecasting literature. It examines tourism demand forecasting from the new perspective of scenario forecasting, in which scenarios are constructed based on two variables. To capture the interaction of tourism demand between various destinations, a system model - the TVP-PVAR model - that provides superior performance is introduced to the tourism forecasting field. Moreover, unlike the traditional TVP, in which only coefficients are allowed to vary over time, the TVPPVAR model in this study allows both the coefficients and the error covariance matrix to vary over time. This sheds new light on the application of the TVP model in tourism forecasting.

Furthermore, the findings of this study provide persuasive practical guidance for industry decision making. For example, when the scenario of high tourism demand (i.e., higher tourism export) growth and low economic growth is predicted with a high probability, it is more reasonable to invest in the tourism industry than in other sectors at the destination given limited resources. In contrast, when the scenario of low tourism demand (i.e., tourism export) growth and high economic growth is predicted with a high probability, investment in tourism-related industries may not be the optimal business decision. In addition, when the scenario of low tourism demand growth and low economic growth is predicted with a high probability, business decisions should be less aggressive owing to the recession in both tourism and overall economic markets. Aggressive decision-making is more suitable for the scenario in which both tourism demand and economic growth rates are high. The values of the probabilities predicted for various scenarios provide practitioners with the knowledge and confidence to make such business decisions.

The findings of this study suggest several future research directions. First, various versions of the TVP-PVAR models are examined in this study, and on average, the TVP $(\kappa)$ VAR model demonstrates superior forecasting ability. In future studies, different levels of 
time variation for parameters and error covariance matrices could be tested to examine the model's generalizability and provide more evidence of its superiority. Second, this study constructs scenarios and events using both tourism exports and the destination's economic growth as variables. In future studies, different types of scenarios or events could be tested using different variables. Third, this study uses a TVP technique in which both the coefficients and the variances of the error terms are allowed to vary over time. It would be interesting to explore whether this setting works for traditional tourism demand forecasting, and a comparative examination would be worthwhile.

\section{REFERENCES}

Assaf, A. G., Li, G., Song, H., \& Tsionas, M. G. (2019). Modeling and forecasting regional tourism demand using the Bayesian global vector autoregressive (BGVAR) model. Journal of Travel Research, 58(3), 383-397.

Athanasopoulos, G., Hyndman, R. J., Song, H., \& Wu, D. C. (2011). The tourism forecasting competition. International Journal of Forecasting, 27(3), 822-844.

Artus, J. R. (1972). An econometric analysis of international travel. Staff PapersInternational Monetary Fund, 19(3), 579-614.

Brida, J. G., Cortes-Jimenez, I., \& Pulina, M.(2016). Has the tourism-led growth hypothesis been validated? A literature review. Current Issues in Tourism 19 (5): 394-430.

Brier, G. W. (1950). Verification of forecasts expressed in terms of probability. Monthly Weather Review, 78(1), 1-3.

Bröcker, J., \& Smith, L. A. (2007). Scoring probabilistic forecasts: The importance of being proper. Weather and Forecasting, 22(2), 382-388.

Bussière, M., Chudik, A., \& Sestieri, G. (2009). Modelling global trade flows: Results from a GVAR model. Working Paper Series 1087, European Central Bank. Retrieved May 5, 2019 from: http://www.ecb.europa.eu/pub/pdf/scpwps/ecbwp1087.pdf. 
Canova, F., \& Ciccarelli, M. (2004). Forecasting and turning point predictions in a Bayesian panel VAR model. Journal of Econometrics, 120(2), 327-359.

Canova, F., \& Ciccarelli, M. (2009). Estimating multicountry VAR models. International Economic Review, 50(3), 929-959.

Cao, Z., Li, G., \& Song, H. (2017). Modelling the interdependence of tourism demand: The global vector autoregressive approach. Annals of Tourism Research, 67, 1-13.

Christoffersen, P. F. (1998). Evaluating interval forecasts. International Economic Review, 39, $841-862$.

Dangl, T., \& Halling, M. (2012). Predictive regressions with time-varying coefficients. Journal of Financial Economics, 106(1), 157-181.

Dees, S., Mauro, F. D., Pesaran, M. H., \& Smith, L. V. (2007). Exploring the international linkages of the euro area: A global VAR analysis. Journal of Applied Econometrics, 22(1), 1-38.

Eeckels, B., Filis, G., \& Leon, C. (2012). Tourism income and economic growth in Greece: empirical evidence from their cyclical components. Tourism Economics, 18(4), 817834.

Favero, C. A. (2013). Modelling and forecasting government bond spreads in the euro area: A GVAR model. Journal of Econometrics, 177(2), 343-356.

Garratt, A., Lee, K., Pesaran, M. H., \& Shin, Y. (2003). Forecast uncertainties in macroeconomic modelling: An application to the UK economy. Journal of the American Statistical Association, 98(464), 829-838.

Gray, H. P. (1966). The demand for international travel by the United States and Canada. International Economic Review, 7(1), 83-92. 
Greenwood-Nimmo, M., Nguyen, V. H., \& Shin, Y. (2012). Probabilistic forecasting of output growth, inflation and the balance of trade in a GVAR framework. Journal of Applied Econometrics, 27(4), 554-573.

Grossmann, A., Love, I., \& Orlov, A. G. (2014). The dynamics of exchange rate volatility: A panel VAR approach. Journal of International Financial Markets, Institutions and Money, 33, 1-27.

Hall, C. M. (2010). Crisis events in tourism: Subjects of crisis in tourism. Current Issues in Tourism, 13(5), 401-417.

Hausmann, R., Pritchett, L., \& Rodrik, D. (2005). Growth accelerations. Journal of Economic Growth, 10(4), 303-329.

International Monetary Fund (2009). Balance of Payments and International Investment Position Manual, Sixth edition, IMF Multimedia Services Division, 2009.

Jong-A-Pin, R., \& De Haan, J. (2011). Political regime change, economic liberalization and growth accelerations. Public Choice, 146(1-2), 93-115.

Kim, J. H., Song, H., \& Wong, K. K. F. (2010). Bias-corrected bootstrap prediction intervals for autoregressive model: New alternatives with applications to tourismforecasting. Journal of Forecasting, 29(7), 655-672.

Kim, J. H., Wong, K., Athanasopoulos, G., \& Liu, S. (2011). Beyond point forecasting: Evaluation of alternative prediction intervals for tourist arrivals. InternationalJournal of Forecasting, 27(3), 887-901.

Koop, G., \& Korobilis, D. (2019). Forecasting with high-dimensional panel VARs. Oxford Bulletin of Economics and Statistics. DOI:10.1111/obes.12303

Lewis, C., \& Pain, N. (2015). Lessons from OECD forecasts during and after the financial crisis. OECD Journal: Economic Studies2014, 1, 9-39. 
Li, G., Song, H. Y., \& Witt, S. F. (2006). Time varying parameter and fixed parameter linear AIDS: An application to tourism demand forecasting. International Journal of Forecasting, 22(1), 57-71.

Li, G., \& Wu, D. C. (2019). Introduction to the special focus: Tourism forecasting-New trends and issues. Tourism Economics, 25(3), 305-308.

Li, G., Wu, D. C., Zhou, M., \& Liu, A. (2019). The combination of interval forecasts in tourism. Annals of Tourism Research, 75, 363-378.

Liu, A., \& Wu, D. C.(2019). Tourism productivity and economic growth. Annals of Tourism Research 76, 253-265.

Lof, M., \& Malinen, T. (2014). Does sovereign debt weaken economic growth? A panel VAR analysis. Economics Letters, 122(3), 403-407.

Mahadevan, R., \& Suardi, S. (2019). Panel evidence on the impact of tourism growth on poverty, poverty gap and income inequality. Current Issues in Tourism, 22(3), 253264.

Moriarty, J. P. (2012). Theorising scenario analysis to improve future perspective planning in tourism. Journal of Sustainable Tourism, 20(6), 779-800.

Nunkoo, R., Seetanah, B., Jaffur, Z. R. K., Moraghen, P. G. W., \& Sannassee, R. V. (2019). Tourism and economic growth: A meta-regression analysis. Journal of Travel Research. Published online May 29. doi: 10.1177/0047287519844833.

Page, S., Song, H., \& Wu, D. C. (2012). Assessing the impacts of the global economic crisis and swine flu on inbound tourism demand in the United Kingdom. Journal of Travel Research, 51(2), 142-153.

Page, S. J., Yeoman, I., Connell, J., \& Greenwood, C. (2010). Scenario planning as a tool to understand uncertainty in tourism: The example of transport and tourism in Scotland in 2025. Current Issues in Tourism, 13(2), 99-137. 
Pesaran, M. H., Schuermann, T., \& Smith, L. V. (2009). Forecasting economic and financial variables with global VARs. International Journal of Forecasting, 25(4), 642-675.

Pesaran, M. H., Schuermann, T., \& Weiner, S. M. (2004). Modeling regional interdependencies using a global error-correcting macroeconometric model. Journal of Business \& Economic Statistics, 22(2), 129-162.

Raftery, A. E., Kárný, M., \& Ettler, P. (2010). Online prediction under model uncertainty via dynamic model averaging: Application to a cold rolling mill. Technometrics, 52(1), $52-66$.

Ringbeck, J., \& Pietsch, T. (2013). How to succeed as a tourism destination in a volatile world. The Travel \& Tourism Competitiveness Report 2013, 43.

Smeral, E. (2004). Long-term forecasts for international tourism. Tourism Economics, 10(2), $145-166$.

Smeral, E., \& Witt, S. F. (1996). Econometric forecasts of tourism demand to 2005. Annals of Tourism Research, 23(4), 891-907.

Smeral, E., \& Weber, A. (2000). Forecasting international tourism trends to 2010. Annals of Tourism Research, 27(4), 982-1006.

Song, H, Qiu, R. T. R., \& Park, J. (2019). A review of research on tourism demand forecasting. Annals of Tourism Research, 75, 338-362.

Song, H., \& Li, G. (2008). Tourism demand modelling and forecasting-A review of recent research. Tourism Management, 29(2), 203-220.

Song, H., Witt, S. F., \& Li, G. (2009). The Advanced Econometrics of Tourism Demand. London; New York: Routledge.

Stankov, P. (2018). Deregulation, Economic Growth and Growth Acceleration. Journal of Economic Development, 43(4), 21-40. 
van Doorn, J. W. (1986). Scenario writing: A method for long-term tourism forecasting? Tourism Management, 7(1), 33-49.

Wang, Y. S. (2009). The impact of crisis events and macroeconomic activity on Taiwan's international inbound tourism demand. Tourism Management, 30(1), 75-82.

Wang, Y. S. (2014). Effects of budgetary constraints on international tourism expenditures.

Tourism Management, 41, 9-18.

Wu, D. C., Liu, J., Song, H., Liu, A., \& Fu, H. (2019). Developing a web-based regional tourism satellite account (TSA) information system. Tourism Economics, 25(1), 6784.

Wu, D. C., Song, H., \& Shen, S. (2017). New developments in tourism and hotel demand modeling and forecasting. International Journal of Contemporary Hospitality Management, 29(1), 507-529. 
Table 1. Summary of Data Sources.

\begin{tabular}{|c|c|c|c|}
\hline Variable & Measure & Frequency & Source \\
\hline Tourism imports & $\begin{array}{l}\text { Travel debits (million } \\
\text { US\$), passenger transport } \\
\text { debits (million US\$) }\end{array}$ & Quarterly & $\begin{array}{l}\text { Balance of Payments } \\
\text { Statistics Yearbook, IMF }\end{array}$ \\
\hline Tourism exports & $\begin{array}{l}\text { Travel credits (million } \\
\text { US\$), passenger transport } \\
\text { credits (million US\$) }\end{array}$ & Quarterly & $\begin{array}{l}\text { Balance of Payments } \\
\text { Statistics Yearbook, IMF }\end{array}$ \\
\hline Real GDP index & $\begin{array}{l}\text { Real GDP index (base } \\
\text { year } 2005=100 \text { ) }\end{array}$ & Quarterly & $\begin{array}{l}\text { International Financial } \\
\text { Statistics, IMF; national } \\
\text { statistical offices }\end{array}$ \\
\hline Consumer price index & $\begin{array}{l}\text { CPI (base year } 2005= \\
100)\end{array}$ & Quarterly & $\begin{array}{l}\text { International Financial } \\
\text { Statistics, IMF; main } \\
\text { economic indicators, } \\
\text { OECD }\end{array}$ \\
\hline Exchange rates & $\begin{array}{l}\text { National currency against } \\
\text { US\$ }\end{array}$ & Quarterly & $\begin{array}{l}\text { International Financial } \\
\text { Statistics, IMF }\end{array}$ \\
\hline Bilateral trade volume & $\begin{array}{l}\text { Average of exports and } \\
\text { imports (in US\$) }\end{array}$ & Annual & $\begin{array}{l}\text { Direction of Trade } \\
\text { Statistics, IMF }\end{array}$ \\
\hline
\end{tabular}

Note: All data cover the period from 1993Q1 to 2016Q4. 
Table 2. Accuracy Rates for Each Country in the System for Eight Forecast Horizons.

\begin{tabular}{|c|c|c|c|c|c|c|c|c|c|c|c|c|c|c|c|c|c|c|c|c|c|c|c|c|c|c|}
\hline & AUS & EL & RA & AN & $\mathrm{CHN}$ & RA & EU & IND & ITA & JPN & OR & MEX & NLD & NZL & IOR & PHL & PRT & SGP & SVN & $\mathrm{ZAF}$ & ESP & SWE & THA & GBR & USA & Average \\
\hline & $\underline{h=1}$ & & & & & & & & & & & & & & & & & & & & & & & & & \\
\hline $\operatorname{VAR}(1)$ & 0.500 & 0.375 & 0.438 & 0.219 & 0.438 & 0.313 & 0.438 & 0.313 & 0.344 & 0.438 & 0.406 & 0.344 & 0.438 & 0.469 & 0.531 & 0.375 & 0.344 & 0.438 & 0.469 & 0.344 & 0.344 & 0.406 & 0.500 & 0.375 & 0.406 & 0.400 \\
\hline $\operatorname{VAR}(2)$ & 0.500 & 0.313 & 0.469 & 0.313 & 0.406 & 0.250 & 0.406 & 0.281 & 0.344 & 0.438 & 0.344 & 0.375 & 0.500 & 0.438 & 0.500 & 0.406 & 0.313 & 0.500 & 0.438 & 0.375 & 0.313 & 0.281 & 0.406 & 0.313 & 0.500 & 0.389 \\
\hline PVAR & 0.219 & 0.500 & 0.281 & 0.281 & 0.375 & 0.281 & 0.281 & 0.156 & 0.125 & 0.125 & 0.250 & 0.125 & 0.281 & 0.188 & 0.281 & 0.500 & 0.250 & 0.406 & 0.156 & 0.500 & 0.219 & 0.281 & 0.250 & 0.313 & 0.188 & 0.273 \\
\hline TVP $(\lambda)$-PVAR & 0.250 & 0.313 & 0.344 & 0.313 & 0.344 & 0.281 & 0.156 & 0.219 & 0.344 & 0.344 & 0.219 & 0.344 & 0.250 & 0.281 & 0.188 & 0.281 & 0.250 & 0.344 & 0.313 & 0.281 & 0.281 & 0.250 & 0.281 & 0.250 & 0.375 & 0.284 \\
\hline TVP( $(\kappa)-\mathrm{PVAR}$ & 0.500 & 0.375 & 0.469 & 0.281 & 0.406 & 0.281 & 0.375 & 0.344 & 0.500 & 0.406 & 0.406 & 0.281 & 0.375 & 0.469 & 0.563 & 0.500 & 0.438 & 0.531 & 0.406 & 0.281 & 0.406 & 0.531 & 0.531 & 0.438 & 0.375 & 0.419 \\
\hline \multirow[t]{2}{*}{ TVP $(\lambda \kappa)$-PVAR } & 0.375 & 0.406 & 0.313 & 0.250 & 0.344 & 0.281 & 0.469 & 0.313 & 0.375 & 0.438 & 0.406 & 0.375 & 0.344 & 0.438 & 0.594 & 0.406 & 0.375 & 0.469 & 0.406 & 0.344 & 0.344 & 0.500 & 0.438 & 0.500 & 0.406 & 0.396 \\
\hline & $\underline{h=2}$ & & & & & & & & & & & & & & & & & & & & & & & & & \\
\hline $\operatorname{VAR}(1)$ & 0.419 & 0.387 & 0.387 & 0.387 & 0.258 & 0.323 & 0.452 & 0.355 & 0.258 & 0.387 & 0.355 & 0.290 & 0.323 & 0.323 & 0.355 & 0.419 & 0.355 & 0.452 & 0.516 & 0.419 & 0.323 & 0.323 & 0.516 & 0.226 & 0.258 & 0.363 \\
\hline $\operatorname{VAR}(2)$ & 0.258 & 0.419 & 0.290 & 0.387 & 0.194 & 0.290 & 0.323 & 0.419 & 0.452 & 0.290 & 0.290 & 0.290 & 0.419 & 0.258 & 0.452 & 0.452 & 0.290 & 0.355 & 0.387 & 0.355 & 0.387 & 0.387 & 0.484 & 0.194 & 0.323 & 0.346 \\
\hline PVAR & 0.258 & 0.194 & 0.290 & 0.323 & 0.387 & 0.323 & 0.129 & 0.258 & 0.226 & 0.355 & 0.290 & 0.258 & 0.258 & 0.161 & 0.258 & 0.258 & 0.226 & 0.452 & 0.258 & 0.323 & 0.387 & 0.226 & 0.419 & 0.419 & 0.226 & 0.286 \\
\hline TVP $(\lambda)$-PVAR & 0.258 & 0.161 & 0.355 & 0.290 & 0.161 & 0.226 & 0.226 & 0.258 & 0.226 & 0.355 & 0.387 & 0.226 & 0.226 & 0.194 & 0.226 & 0.258 & 0.355 & 0.258 & 0.161 & 0.226 & 0.258 & 0.194 & 0.323 & 0.194 & 0.258 & 0.250 \\
\hline $\operatorname{TVP}(\kappa)-\mathrm{PVAR}$ & 0.452 & 0.387 & 0.452 & 0.290 & 0.258 & 0.258 & 0.484 & 0.323 & 0.355 & 0.419 & 0.355 & 0.323 & 0.323 & 0.290 & 0.484 & 0.419 & 0.323 & 0.419 & 0.484 & 0.516 & 0.452 & 0.419 & 0.484 & 0.387 & 0.355 & 0.388 \\
\hline \multirow[t]{2}{*}{ TVP( $(\lambda \kappa)$-PVAR } & 0.355 & 0.258 & 0.387 & 0.355 & 0.290 & 0.258 & 0.387 & 0.258 & 0.290 & 0.452 & 0.355 & 0.387 & 0.258 & 0.355 & 0.452 & 0.387 & 0.452 & 0.258 & 0.452 & 0.355 & 0.387 & 0.387 & 0.516 & 0.387 & 0.419 & 0.364 \\
\hline & $\underline{h=3}$ & & & & & & & & & & & & & & & & & & & & & & & & & \\
\hline $\operatorname{VAR}(1)$ & 0.333 & 0.333 & 0.367 & 0.400 & 0.267 & 0.300 & 0.300 & 0.467 & 0.300 & 0.367 & 0.400 & 0.233 & 0.400 & 0.367 & 0.433 & 0.367 & 0.267 & 0.400 & 0.433 & 0.300 & 0.333 & 0.267 & 0.333 & 0.400 & 0.333 & 0.348 \\
\hline $\operatorname{VAR}(2)$ & 0.333 & 0.300 & 0.267 & 0.333 & 0.367 & 0.233 & 0.400 & 0.400 & 0.300 & 0.367 & 0.333 & 0.267 & 0.300 & 0.367 & 0.300 & 0.400 & 0.300 & 0.400 & 0.467 & 0.333 & 0.333 & 0.400 & 0.367 & 0.300 & 0.233 & 0.336 \\
\hline PVAR & 0.133 & 0.167 & 0.367 & 0.267 & 0.267 & 0.333 & 0.200 & 0.400 & 0.300 & 0.367 & 0.200 & 0.233 & 0.267 & 0.400 & 0.400 & 0.233 & 0.267 & 0.167 & 0.267 & 0.200 & 0.167 & 0.333 & 0.100 & 0.533 & 0.267 & 0.273 \\
\hline TVP( $(\lambda)$-PVAR & 0.233 & 0.167 & 0.267 & 0.333 & 0.333 & 0.333 & 0.267 & 0.333 & 0.133 & 0.233 & 0.267 & 0.333 & 0.367 & 0.367 & 0.400 & 0.233 & 0.200 & 0.267 & 0.333 & 0.200 & 0.200 & 0.400 & 0.200 & 0.300 & 0.300 & 0.280 \\
\hline TVP( $(\kappa)$-PVAR & 0.367 & 0.300 & 0.433 & 0.333 & 0.300 & 0.300 & 0.367 & 0.433 & 0.267 & 0.333 & 0.267 & 0.233 & 0.233 & 0.300 & 0.433 & 0.300 & 0.267 & 0.400 & 0.500 & 0.267 & 0.333 & 0.500 & 0.400 & 0.233 & 0.300 & 0.336 \\
\hline \multirow[t]{2}{*}{ TVP $(\lambda \kappa)-\mathrm{PVAR}$} & 0.400 & 0.300 & 0.400 & 0.400 & 0.267 & 0.400 & 0.500 & 0.433 & 0.300 & 0.367 & 0.367 & 0.267 & 0.267 & 0.300 & 0.500 & 0.333 & 0.333 & 0.333 & 0.500 & 0.300 & 0.300 & 0.467 & 0.367 & 0.400 & 0.400 & 0.368 \\
\hline & $\underline{h=4}$ & & & & & & & & & & & & & & & & & & & & & & & & & \\
\hline $\operatorname{VAR}(1)$ & 0.207 & 0.310 & 0.207 & 0.379 & 0.241 & 0.276 & 0.207 & 0.241 & 0.345 & 0.276 & 0.310 & 0.483 & 0.345 & 0.310 & 0.379 & 0.345 & 0.379 & 0.552 & 0.310 & 0.207 & 0.379 & 0.207 & 0.310 & 0.448 & 0.276 & 0.317 \\
\hline $\operatorname{VAR}(2)$ & 0.241 & 0.345 & 0.172 & 0.276 & 0.379 & 0.241 & 0.345 & 0.345 & 0.379 & 0.241 & 0.310 & 0.345 & 0.310 & 0.310 & 0.276 & 0.276 & 0.379 & 0.483 & 0.345 & 0.172 & 0.310 & 0.379 & 0.310 & 0.414 & 0.276 & 0.314 \\
\hline PVAR & 0.310 & 0.138 & 0.448 & 0.276 & 0.241 & 0.172 & 0.207 & 0.241 & 0.103 & 0.276 & 0.276 & 0.414 & 0.138 & 0.379 & 0.276 & 0.310 & 0.207 & 0.207 & 0.276 & 0.241 & 0.138 & 0.310 & 0.241 & 0.241 & 0.345 & 0.257 \\
\hline TVP( $(\lambda)$-PVAR & 0.172 & 0.414 & 0.276 & 0.207 & 0.345 & 0.276 & 0.414 & 0.069 & 0.379 & 0.241 & 0.207 & 0.345 & 0.276 & 0.345 & 0.172 & 0.310 & 0.241 & 0.310 & 0.241 & 0.345 & 0.207 & 0.172 & 0.276 & 0.241 & 0.207 & 0.268 \\
\hline TVP $(\kappa)-\mathrm{PVAR}$ & 0.345 & 0.379 & 0.276 & 0.345 & 0.241 & 0.207 & 0.379 & 0.241 & 0.241 & 0.345 & 0.310 & 0.448 & 0.310 & 0.345 & 0.379 & 0.345 & 0.310 & 0.586 & 0.379 & 0.276 & 0.379 & 0.310 & 0.241 & 0.483 & 0.310 & 0.337 \\
\hline TVP( $(\lambda \kappa)-\mathrm{PVAR}$ & 0.310 & 0.379 & 0.379 & 0.310 & 0.241 & 0.345 & 0.414 & 0.310 & 0.345 & 0.310 & 0.276 & 0.345 & 0.207 & 0.414 & 0.552 & 0.241 & 0.310 & 0.483 & 0.345 & 0.207 & 0.414 & 0.345 & 0.310 & 0.586 & 0.310 & 0.348 \\
\hline
\end{tabular}




\begin{tabular}{|c|c|c|c|c|c|c|c|c|c|c|c|c|c|c|c|c|c|c|c|c|c|c|c|c|c|c|}
\hline & $=5$ & & & & & & & & & & & & & & & & & & & & & & & & & \\
\hline $\operatorname{VAR}(1)$ & 0.321 & 0.321 & 0.179 & 0.393 & 0.250 & 0.286 & 0.250 & 0.250 & 0.321 & 0.179 & 0.321 & 0.107 & 0.286 & 0.214 & 0.286 & 0.214 & 0.286 & 0.214 & 0.429 & 0.179 & 0.393 & 0.321 & 0.250 & 0.143 & 0.179 & 0.263 \\
\hline $\operatorname{VAR}(2)$ & 0.321 & 0.250 & 0.143 & 0.357 & 0.321 & 0.250 & 0.357 & 0.321 & 0.286 & 0.321 & 0.429 & 0.429 & 0.179 & 0.321 & 0.107 & 0.214 & 0.464 & 0.536 & 0.571 & 0.286 & 0.286 & 0.179 & 0.214 & 0.286 & 0.357 & 0.311 \\
\hline PVAR & 0.357 & 0.214 & 0.250 & 0.357 & 0.286 & 0.214 & 0.107 & 0.250 & 0.321 & 0.179 & 0.286 & 0.286 & 0.214 & 0.286 & 0.250 & 0.214 & 0.179 & 0.321 & 0.321 & 0.214 & 0.179 & 0.214 & 0.321 & 0.286 & 0.357 & .259 \\
\hline TVP( $(\lambda)$-PVAR & 0.321 & 0.214 & 0.286 & 0.179 & 0.250 & 0.250 & 0.321 & 0.429 & 0.179 & 0.393 & 0.286 & 0.321 & 0.321 & 0.393 & 0.286 & 0.143 & 0.357 & 0.393 & 0.250 & 0.143 & 0.321 & 0.179 & 0.214 & 0.214 & 0.286 & .277 \\
\hline TVP $(\kappa)-\mathrm{PVAR}$ & 0.286 & 0.286 & 0.214 & 0.214 & 0.143 & 0.143 & 0.321 & 0.179 & 0.393 & 0.536 & 0.321 & 0.321 & 0.250 & 0.321 & 0.214 & 0.179 & 0.464 & 0.357 & 0.429 & 0.286 & 0.250 & 0.214 & 0.393 & 0.179 & 0.286 & 0.287 \\
\hline \multirow[t]{2}{*}{$\operatorname{TVP}(\lambda \kappa)$-PVAR } & 0.393 & 0.179 & 0.393 & 0.143 & 0.214 & 0.143 & 0.286 & 0.429 & 0.250 & 0.429 & 0.321 & 0.214 & 0.250 & 0.214 & 0.250 & 0.179 & 0.286 & 0.321 & 0.286 & 0.179 & 0.214 & 0.286 & 0.464 & 0.321 & 0.286 & 0.277 \\
\hline & $\underline{h=6}$ & & & & & & & & & & & & & & & & & & & & & & & & & \\
\hline $\operatorname{VAR}(1)$ & 0.296 & 0.222 & 0.185 & 0.370 & 0.296 & 0.296 & 0.185 & 0.074 & 0.222 & 0.333 & 0.185 & 0.185 & 0.148 & 0.333 & 0.222 & 0.148 & 0.333 & 0.333 & 0.296 & 0.148 & 0.296 & 0.296 & 0.259 & 0.296 & 0.296 & 0.250 \\
\hline $\operatorname{VAR}(2)$ & 0.333 & 0.444 & 0.074 & 0.370 & 0.296 & 0.259 & 0.556 & 0.222 & 0.333 & 0.370 & 0.259 & 0.259 & 0.222 & 0.259 & 0.222 & 0.222 & 0.519 & 0.444 & 0.519 & 0.185 & 0.333 & 0.296 & 0.296 & 0.370 & 0.259 & 0.317 \\
\hline PVAR & 0.296 & 0.296 & 0.222 & 0.259 & 0.111 & 0.333 & 0.148 & 0.407 & 0.259 & 0.222 & 0.333 & 0.333 & 0.333 & 0.296 & 0.259 & 0.185 & 0.333 & 0.296 & 0.259 & 0.296 & 0.148 & 0.259 & 0.259 & 0.259 & 0.185 & 0.264 \\
\hline TVP( $(\lambda)$-PVAR & 0.296 & 0.111 & 0.333 & 0.296 & 0.444 & 0.259 & 0.111 & 0.259 & 0.222 & 0.185 & 0.296 & 0.111 & 0.222 & 0.333 & 0.370 & 0.222 & 0.148 & 0.222 & 0.185 & 0.296 & 0.222 & 0.333 & 0.222 & 0.259 & 0.185 & 0.246 \\
\hline TVP( $(\kappa)-\mathrm{PVAR}$ & 0.407 & 0.074 & 0.333 & 0.259 & 0.259 & 0.370 & 0.333 & 0.259 & 0.296 & 0.370 & 0.370 & 0.222 & 0.259 & 0.296 & 0.481 & 0.444 & 0.444 & 0.519 & 0.259 & 0.370 & 0.296 & 0.259 & 0.333 & 0.296 & 0.222 & 0.321 \\
\hline \multirow[t]{2}{*}{$\operatorname{TVP}(\lambda \kappa)$-PVAR } & 0.370 & 0.259 & 0.370 & 0.222 & 0.407 & 0.333 & 0.259 & 0.370 & 0.296 & 0.148 & 0.296 & 0.259 & 0.296 & 0.222 & 0.296 & 0.222 & 0.148 & 0.185 & 0.481 & 0.222 & 0.407 & 0.259 & 0.222 & 0.222 & 0.259 & 0.281 \\
\hline & $\underline{h=7}$ & & & & & & & & & & & & & & & & & & & & & & & & & \\
\hline $\operatorname{VAR}(1)$ & 0.385 & 0.308 & 0.231 & 0.385 & 0.385 & 0.308 & 0.269 & 0.269 & 0.192 & 0.269 & 0.308 & 0.346 & 0.231 & 0.269 & 0.308 & 0.269 & 0.385 & 0.500 & 0.346 & 0.192 & 0.231 & 0.231 & 0.269 & 0.269 & 0.346 & 0.300 \\
\hline $\operatorname{VAR}(2)$ & 0.231 & 0.346 & 0.154 & 0.462 & 0.346 & 0.231 & 0.423 & 0.269 & 0.269 & 0.462 & 0.154 & 0.385 & 0.115 & 0.385 & 0.231 & 0.308 & 0.385 & 0.385 & 0.385 & 0.231 & 0.385 & 0.269 & 0.231 & 0.269 & 0.346 & 0.306 \\
\hline PVAR & 0.346 & 0.077 & 0.308 & 0.231 & 0.385 & 0.346 & 0.346 & 0.231 & 0.154 & 0.115 & 0.192 & 0.231 & 0.115 & 0.269 & 0.192 & 0.346 & 0.269 & 0.308 & 0.308 & 0.115 & 0.154 & 0.192 & 0.308 & 0.077 & 0.269 & 0.235 \\
\hline TVP( $(\lambda)$-PVAR & 0.423 & 0.346 & 0.115 & 0.308 & 0.154 & 0.115 & 0.154 & 0.115 & 0.192 & 0.231 & 0.308 & 0.462 & 0.154 & 0.154 & 0.192 & 0.269 & 0.231 & 0.154 & 0.269 & 0.346 & 0.231 & 0.308 & 0.269 & 0.077 & 0.269 & 0.234 \\
\hline TVP $(\kappa)-\mathrm{PVAR}$ & 0.231 & 0.192 & 0.462 & 0.269 & 0.231 & 0.115 & 0.269 & 0.269 & 0.346 & 0.308 & 0.423 & 0.154 & 0.346 & 0.269 & 0.308 & 0.385 & 0.269 & 0.423 & 0.308 & 0.308 & 0.269 & 0.346 & 0.346 & 0.192 & 0.308 & 0.294 \\
\hline \multirow[t]{2}{*}{$\operatorname{TVP}(\lambda \kappa)-\mathrm{PVAR}$} & 0.423 & 0.269 & 0.231 & 0.346 & 0.231 & 0.115 & 0.192 & 0.115 & 0.269 & 0.269 & 0.308 & 0.346 & 0.192 & 0.346 & $\mathbf{0 . 3 8 5}$ & $\mathbf{0 . 3 8 5}$ & 0.346 & 0.269 & $\mathbf{0 . 3 8 5}$ & 0.231 & 0.269 & 0.231 & 0.385 & 0.346 & 0.308 & 0.288 \\
\hline & $\underline{h=8}$ & & & & & & & & & & & & & & & & & & & & & & & & & \\
\hline $\operatorname{VAR}(1)$ & 0.440 & 0.120 & 0.080 & 0.360 & 0.360 & 0.120 & 0.360 & 0.200 & 0.160 & 0.320 & 0.360 & 0.200 & 0.400 & 0.280 & 0.200 & 0.240 & 0.400 & 0.360 & 0.440 & 0.240 & 0.280 & 0.320 & 0.200 & 0.320 & 0.400 & 0.286 \\
\hline $\operatorname{VAR}(2)$ & 0.320 & 0.280 & 0.240 & 0.360 & 0.240 & 0.320 & 0.400 & 0.240 & 0.280 & 0.240 & 0.240 & 0.120 & 0.120 & 0.240 & 0.360 & 0.320 & 0.400 & 0.360 & 0.280 & 0.200 & 0.360 & 0.240 & 0.360 & 0.200 & 0.360 & 0.283 \\
\hline PVAR & 0.360 & 0.240 & 0.160 & 0.240 & 0.200 & 0.160 & 0.240 & 0.040 & 0.160 & 0.360 & 0.560 & 0.280 & 0.160 & 0.200 & 0.200 & 0.360 & 0.200 & 0.280 & 0.400 & 0.200 & 0.200 & 0.240 & 0.160 & 0.320 & 0.280 & 0.248 \\
\hline TVP $(\lambda)$-PVAR & 0.200 & 0.240 & 0.200 & 0.120 & 0.280 & 0.240 & 0.320 & 0.320 & 0.240 & 0.240 & 0.280 & 0.240 & 0.160 & 0.160 & 0.400 & 0.280 & 0.120 & 0.200 & 0.360 & 0.240 & 0.320 & 0.200 & 0.160 & 0.200 & 0.360 & 0.243 \\
\hline TVP( $(\kappa)-\mathrm{PVAR}$ & 0.280 & 0.320 & 0.200 & 0.120 & 0.120 & 0.240 & 0.320 & 0.200 & 0.320 & 0.160 & 0.360 & 0.240 & 0.240 & 0.200 & 0.280 & 0.240 & 0.360 & 0.280 & 0.320 & 0.240 & 0.440 & 0.160 & 0.360 & 0.160 & 0.440 & 0.264 \\
\hline $\operatorname{TVP}(\lambda \kappa)$-PVAR & 0.480 & 0.120 & 0.320 & 0.200 & 0.160 & 0.240 & 0.440 & 0.280 & 0.440 & 0.440 & 0.160 & 0.200 & 0.200 & 0.400 & 0.160 & 0.240 & 0.440 & 0.480 & 0.360 & 0.200 & 0.400 & 0.280 & 0.360 & 0.200 & 0.240 & 0.298 \\
\hline
\end{tabular}

Note: VAR $(i)$ refers to the VAR model with $i$ lags. $\lambda($ or $\kappa)$ indicates a time-varying setting for parameters (or error covariance matrix) with $\lambda$ (ork) set as 0.9 . 
Table 3. Brier Scores for Each Country in the System for Eight Forecast Horizons.

\begin{tabular}{|c|c|c|c|c|c|c|c|c|c|c|c|c|c|c|c|c|c|c|c|c|c|c|c|c|c|c|}
\hline & AUS & BEL & BRA & CAN & $\mathrm{CHN}$ & FRA & DEU & IND & ITA & JPN & KOR & MEX & NLD & NZL & NOR & PHL & PRT & SGP & SVN & $\mathrm{ZAF}$ & ESP & SWE & THA & GBR & USA & Average \\
\hline & $\underline{h=1}$ & & & & & & & & & & & & & & & & & & & & & & & & & \\
\hline $\operatorname{VAR}(1)$ & 0.644 & 0.713 & 0.704 & 0.757 & 0.701 & 0.773 & 0.678 & 0.756 & 0.722 & 0.647 & 0.709 & 0.723 & 0.723 & 0.672 & 0.629 & 0.686 & 0.750 & 0.703 & 0.711 & 0.690 & 0.758 & 0.727 & 0.629 & 0.685 & 0.685 & 0.703 \\
\hline $\operatorname{VAR}(2)$ & 0.651 & 0.775 & 0.751 & 0.771 & 0.697 & 0.774 & 0.733 & 0.746 & 0.732 & 0.634 & 0.736 & 0.796 & 0.711 & 0.665 & 0.624 & 0.676 & 0.798 & 0.686 & 0.755 & 0.738 & 0.776 & 0.734 & 0.666 & 0.736 & 0.614 & 0.719 \\
\hline PVAR & 0.753 & 0.738 & 0.739 & 0.753 & 0.739 & 0.743 & 0.745 & 0.752 & 0.764 & 0.760 & 0.734 & 0.758 & 0.749 & 0.762 & 0.754 & 0.732 & 0.751 & 0.734 & 0.757 & 0.726 & 0.757 & 0.745 & 0.759 & 0.749 & 0.751 & 0.748 \\
\hline TVP $(\lambda)$-PVAR & 0.762 & 0.745 & 0.746 & 0.745 & 0.744 & 0.750 & 0.757 & 0.755 & 0.739 & 0.745 & 0.746 & 0.745 & 0.750 & 0.754 & 0.759 & 0.733 & 0.746 & 0.744 & 0.747 & 0.750 & 0.754 & 0.755 & 0.751 & 0.755 & 0.739 & 0.749 \\
\hline TVP( $(\kappa)-\mathrm{PVAR}$ & 0.720 & 0.675 & 0.638 & 0.709 & 0.728 & 0.731 & 0.658 & 0.753 & 0.689 & 0.678 & 0.694 & 0.770 & 0.686 & 0.668 & 0.629 & 0.687 & 0.735 & 0.663 & 0.712 & 0.748 & 0.698 & 0.676 & 0.654 & 0.666 & 0.714 & 0.695 \\
\hline \multirow[t]{2}{*}{ TVP $(\lambda \kappa)$-PVAR } & 0.755 & 0.680 & 0.745 & 0.749 & 0.750 & 0.744 & 0.661 & 0.784 & 0.710 & 0.693 & 0.697 & 0.751 & 0.688 & 0.680 & 0.609 & 0.684 & 0.745 & 0.690 & 0.689 & 0.763 & 0.734 & 0.674 & 0.661 & 0.658 & 0.708 & 0.708 \\
\hline & $\underline{h=2}$ & & & & & & & & & & & & & & & & & & & & & & & & & \\
\hline $\operatorname{VAR}(1)$ & 0.699 & 0.733 & 0.729 & 0.746 & 0.740 & 0.776 & 0.687 & 0.715 & 0.755 & 0.719 & 0.705 & 0.753 & 0.758 & 0.730 & 0.711 & 0.702 & 0.742 & 0.714 & 0.690 & 0.697 & 0.820 & 0.744 & 0.693 & 0.794 & 0.711 & 0.730 \\
\hline $\operatorname{VAR}(2)$ & 0.785 & 0.753 & 0.754 & 0.746 & 0.742 & 0.766 & 0.719 & 0.716 & 0.732 & 0.781 & 0.746 & 0.798 & 0.748 & 0.766 & 0.655 & 0.695 & 0.815 & 0.748 & 0.724 & 0.771 & 0.763 & 0.719 & 0.652 & 0.823 & 0.773 & 0.748 \\
\hline PVAR & 0.748 & 0.760 & 0.747 & 0.745 & 0.747 & 0.747 & 0.757 & 0.750 & 0.743 & 0.752 & 0.741 & 0.770 & 0.753 & 0.765 & 0.759 & 0.743 & 0.752 & 0.737 & 0.739 & 0.745 & 0.748 & 0.753 & 0.739 & 0.740 & 0.749 & 0.749 \\
\hline TVP $(\lambda)$-PVAR & 0.748 & 0.754 & 0.744 & 0.752 & 0.759 & 0.751 & 0.742 & 0.753 & 0.755 & 0.744 & 0.732 & 0.756 & 0.745 & 0.758 & 0.753 & 0.750 & 0.748 & 0.753 & 0.755 & 0.750 & 0.757 & 0.759 & 0.741 & 0.753 & 0.749 & 0.750 \\
\hline TVP( $(\kappa)-\mathrm{PVAR}$ & 0.716 & 0.733 & 0.694 & 0.733 & 0.743 & 0.741 & 0.703 & 0.732 & 0.713 & 0.696 & 0.713 & 0.722 & 0.718 & 0.736 & 0.695 & 0.717 & 0.733 & 0.712 & 0.679 & 0.681 & 0.692 & 0.714 & 0.697 & 0.710 & 0.733 & 0.714 \\
\hline \multirow[t]{2}{*}{$\operatorname{TVP}(\lambda \kappa)$-PVAR } & 0.718 & 0.737 & 0.697 & 0.750 & 0.768 & 0.756 & 0.710 & 0.744 & 0.722 & 0.678 & 0.712 & 0.724 & 0.725 & 0.746 & 0.689 & 0.729 & 0.722 & 0.738 & 0.704 & 0.694 & 0.708 & 0.710 & 0.691 & 0.722 & 0.711 & 0.720 \\
\hline & $\underline{h=3}$ & & & & & & & & & & & & & & & & & & & & & & & & & \\
\hline $\operatorname{VAR}(1)$ & 0.709 & 0.750 & 0.751 & 0.765 & 0.717 & 0.741 & 0.703 & 0.707 & 0.764 & 0.739 & 0.724 & 0.741 & 0.746 & 0.732 & 0.726 & 0.731 & 0.785 & 0.687 & 0.696 & 0.781 & 0.811 & 0.750 & 0.746 & 0.712 & 0.735 & 0.738 \\
\hline $\operatorname{VAR}(2)$ & 0.731 & 0.800 & 0.758 & 0.782 & 0.721 & 0.762 & 0.707 & 0.720 & 0.780 & 0.750 & 0.715 & 0.726 & 0.769 & 0.745 & 0.742 & 0.731 & 0.779 & 0.704 & 0.681 & 0.804 & 0.826 & 0.748 & 0.745 & 0.731 & 0.799 & 0.750 \\
\hline PVAR & 0.754 & 0.760 & 0.740 & 0.743 & 0.754 & 0.741 & 0.749 & 0.746 & 0.741 & 0.744 & 0.748 & 0.742 & 0.756 & 0.740 & 0.744 & 0.753 & 0.746 & 0.765 & 0.737 & 0.748 & 0.761 & 0.735 & 0.758 & 0.732 & 0.761 & 0.748 \\
\hline TVP $(\lambda)$-PVAR & 0.751 & 0.764 & 0.767 & 0.737 & 0.745 & 0.742 & 0.752 & 0.746 & 0.754 & 0.746 & 0.748 & 0.748 & 0.744 & 0.746 & 0.741 & 0.759 & 0.752 & 0.746 & 0.739 & 0.750 & 0.756 & 0.733 & 0.754 & 0.748 & 0.747 & 0.749 \\
\hline TVP( $(\kappa)-\mathrm{PVAR}$ & 0.736 & 0.720 & 0.716 & 0.736 & 0.731 & 0.724 & 0.706 & 0.706 & 0.748 & 0.720 & 0.724 & 0.739 & 0.738 & 0.712 & 0.698 & 0.707 & 0.729 & 0.699 & 0.682 & 0.734 & 0.725 & 0.709 & 0.709 & 0.741 & 0.748 & 0.721 \\
\hline \multirow[t]{2}{*}{ TVP $(\lambda \kappa)$-PVAR } & 0.732 & 0.734 & 0.694 & 0.734 & 0.756 & 0.731 & 0.703 & 0.712 & 0.732 & 0.715 & 0.718 & 0.735 & 0.716 & 0.728 & 0.697 & 0.716 & 0.743 & 0.701 & 0.673 & 0.748 & 0.728 & 0.704 & 0.716 & 0.733 & 0.745 & 0.722 \\
\hline & $\underline{h=4}$ & & & & & & & & & & & & & & & & & & & & & & & & & \\
\hline $\operatorname{VAR}(1)$ & 0.758 & 0.759 & 0.774 & 0.775 & 0.721 & 0.759 & 0.742 & 0.751 & 0.776 & 0.777 & 0.743 & 0.694 & 0.744 & 0.751 & 0.732 & 0.739 & 0.750 & 0.675 & 0.715 & 0.823 & 0.772 & 0.762 & 0.781 & 0.698 & 0.761 & 0.749 \\
\hline $\operatorname{VAR}(2)$ & 0.726 & 0.771 & 0.788 & 0.782 & 0.738 & 0.747 & 0.725 & 0.750 & 0.774 & 0.772 & 0.724 & 0.723 & 0.751 & 0.737 & 0.736 & 0.746 & 0.734 & 0.677 & 0.711 & 0.821 & 0.791 & 0.757 & 0.764 & 0.720 & 0.740 & 0.748 \\
\hline PVAR & 0.747 & 0.761 & 0.738 & 0.749 & 0.751 & 0.757 & 0.752 & 0.745 & 0.759 & 0.741 & 0.761 & 0.750 & 0.756 & 0.743 & 0.746 & 0.741 & 0.754 & 0.760 & 0.747 & 0.752 & 0.749 & 0.748 & 0.753 & 0.763 & 0.751 & 0.751 \\
\hline TVP( $(\lambda)$-PVAR & 0.764 & 0.741 & 0.749 & 0.759 & 0.743 & 0.746 & 0.734 & 0.762 & 0.742 & 0.769 & 0.759 & 0.747 & 0.748 & 0.745 & 0.752 & 0.753 & 0.741 & 0.749 & 0.752 & 0.750 & 0.744 & 0.759 & 0.743 & 0.753 & 0.752 & 0.750 \\
\hline $\operatorname{TVP}(\kappa)-\mathrm{PVAR}$ & 0.747 & 0.717 & 0.741 & 0.743 & 0.746 & 0.752 & 0.730 & 0.739 & 0.759 & 0.734 & 0.730 & 0.708 & 0.727 & 0.719 & 0.702 & 0.715 & 0.736 & 0.690 & 0.696 & 0.768 & 0.725 & 0.748 & 0.745 & 0.699 & 0.745 & 0.730 \\
\hline $\operatorname{TVP}(\lambda \kappa)$-PVAR & 0.735 & 0.728 & 0.727 & 0.746 & 0.740 & 0.748 & 0.726 & 0.748 & 0.742 & 0.740 & 0.739 & 0.717 & 0.739 & 0.723 & 0.705 & 0.739 & 0.731 & 0.691 & 0.695 & 0.764 & 0.726 & 0.731 & 0.740 & 0.706 & 0.749 & 0.731 \\
\hline
\end{tabular}


$\underline{h=5}$

VAR(1)

VAR(2)

PVAR

$\operatorname{TVP}(\lambda)$-PVAR

TVP( $(\kappa)$-PVAR

$\operatorname{TVP}(\lambda \kappa)$-PVAR

VAR(1)

VAR(2)

PVAR

TVP( $(\lambda)$-PVAR

TVP( $(\kappa)$-PVAR

$\operatorname{TVP}(\lambda \kappa)$-PVAR

VAR(1)

VAR(2)

PVAR

TVP( $\lambda$ )-PVAR

TVP( $\kappa)$-PVAR

$\operatorname{TVP}(\lambda \kappa)$-PVAR $\begin{array}{lllllllllllllllllllllllllll}0.747 & 0.781 & 0.781 & 0.763 & 0.758 & \mathbf{0 . 7 5 1} & 0.724 & 0.756 & 0.746 & 0.740 & 0.746 & 0.788 & \mathbf{0 . 7 4 1} & 0.771 & 0.754 & 0.763 & 0.721 & 0.724 & 0.736 & 0.811 & 0.753 & 0.760 & 0.750 & 0.760 & 0.750 & 0.755\end{array}$ $\begin{array}{llllllllllllllllllllllllllll}0.755 & 0.764 & 0.774 & 0.770 & \mathbf{0 . 7 4 5} & 0.770 & \mathbf{0 . 7 1 0} & 0.756 & \mathbf{0 . 7 4 4} & 0.735 & 0.745 & \mathbf{0 . 7 3 2} & 0.767 & 0.760 & 0.780 & 0.778 & \mathbf{0 . 6 8 4} & 0.715 & \mathbf{0 . 7 0 0} & 0.771 & 0.804 & 0.773 & 0.767 & 0.748 & \mathbf{0 . 7 1 4} & 0.750\end{array}$ $\begin{array}{lllllllllllllllllllllllllllll}0.746 & 0.764 & 0.752 & \mathbf{0 . 7 4 8} & 0.751 & \mathbf{0 . 7 5 1} & 0.766 & 0.753 & 0.749 & 0.752 & 0.753 & 0.750 & 0.751 & 0.755 & 0.741 & 0.757 & 0.755 & 0.740 & 0.745 & 0.756 & 0.759 & 0.764 & 0.740 & \mathbf{0 . 7 4 7} & 0.749 & 0.752\end{array}$ $\begin{array}{llllllllllllllllllllllllllll}0.745 & \mathbf{0 . 7 5 2} & 0.747 & 0.760 & 0.751 & 0.756 & 0.744 & \mathbf{0 . 7 4 1} & 0.749 & 0.737 & 0.745 & 0.750 & 0.745 & \mathbf{0 . 7 4 0} & \mathbf{0 . 7 3 7} & 0.758 & 0.749 & 0.743 & 0.744 & 0.765 & 0.744 & \mathbf{0 . 7 5 3} & 0.756 & 0.754 & 0.751 & 0.749\end{array}$ $\begin{array}{lllllllllllllllllllllllllll}\mathbf{0 . 7 3 3} & 0.753 & 0.759 & 0.762 & 0.755 & 0.763 & 0.742 & 0.758 & 0.746 & \mathbf{0 . 7 2 5} & \mathbf{0 . 7 2 9} & 0.755 & 0.772 & 0.750 & 0.744 & \mathbf{0 . 7 4 6} & 0.735 & 0.715 & 0.712 & 0.751 & \mathbf{0 . 7 3 9} & 0.758 & 0.734 & 0.767 & 0.744 & \mathbf{0 . 7 4 6}\end{array}$ $\begin{array}{llllllllllllllllllllllllll}\mathbf{0 . 7 3 3} & 0.760 & \mathbf{0 . 7 2 6} & 0.770 & 0.770 & 0.767 & 0.750 & 0.743 & 0.754 & 0.732 & \mathbf{0 . 7 2 9} & 0.754 & 0.756 & 0.752 & 0.750 & 0.747 & 0.761 & \mathbf{0 . 7 1 2} & 0.720 & \mathbf{0 . 7 5 0} & 0.748 & \mathbf{0 . 7 5 3} & \mathbf{0 . 7 2 8} & 0.753 & 0.759 & 0.747\end{array}$ $\underline{h=6}$

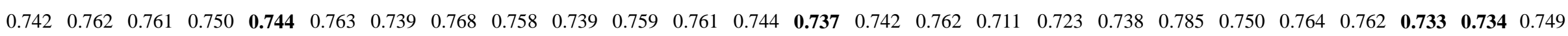
$\begin{array}{lllllllllllllllllllllllllll}\mathbf{0 . 7 3 5} & 0.749 & 0.757 & 0.757 & 0.751 & \mathbf{0 . 7 3 6} & \mathbf{0 . 7 0 5} & 0.758 & 0.759 & \mathbf{0 . 7 3 2} & 0.753 & \mathbf{0 . 7 5 1} & 0.754 & 0.746 & 0.775 & 0.768 & \mathbf{0 . 6 9 2} & \mathbf{0 . 6 9 7} & 0.714 & 0.761 & 0.774 & 0.768 & 0.757 & \mathbf{0 . 7 3 3} & 0.739 & 0.745\end{array}$ $\begin{array}{llllllllllllllllllllllllll}0.750 & \mathbf{0 . 7 4 4} & 0.750 & 0.749 & 0.760 & 0.753 & 0.762 & \mathbf{0 . 7 3 1} & 0.746 & 0.746 & \mathbf{0 . 7 4 3} & 0.753 & \mathbf{0 . 7 3 8} & 0.748 & 0.751 & 0.755 & 0.746 & 0.752 & 0.749 & \mathbf{0 . 7 4 6} & 0.756 & 0.755 & \mathbf{0 . 7 4 2} & 0.751 & 0.755 & 0.749\end{array}$ $\begin{array}{llllllllllllllllllllllllllllll}0.747 & 0.767 & 0.743 & 0.749 & 0.747 & 0.755 & 0.770 & 0.753 & 0.749 & 0.752 & 0.751 & 0.755 & 0.748 & 0.748 & 0.747 & 0.760 & 0.758 & 0.755 & 0.753 & 0.747 & 0.749 & 0.747 & 0.766 & 0.751 & 0.766 & 0.753\end{array}$ $\begin{array}{llllllllllllllllllllllllllllll}0.739 & 0.755 & 0.734 & \mathbf{0 . 7 4 6} & 0.757 & 0.743 & 0.730 & 0.749 & \mathbf{0 . 7 4 5} & 0.735 & 0.752 & 0.756 & 0.761 & 0.746 & \mathbf{0 . 7 2 9} & \mathbf{0 . 7 3 5} & 0.728 & \mathbf{0 . 6 9 7} & 0.728 & 0.754 & 0.734 & 0.765 & 0.756 & 0.748 & 0.754 & \mathbf{0 . 7 4 3}\end{array}$ $\begin{array}{lllllllllllllllllllllllllllll}0.739 & 0.749 & \mathbf{0 . 7 2 4} & 0.761 & 0.750 & 0.743 & 0.727 & 0.749 & 0.750 & 0.746 & 0.749 & 0.755 & 0.749 & 0.757 & 0.742 & 0.750 & 0.748 & 0.715 & \mathbf{0 . 7 0 1} & 0.754 & \mathbf{0 . 7 2 0} & \mathbf{0 . 7 4 6} & 0.751 & 0.762 & 0.754 & 0.744\end{array}$ $\underline{h=7}$

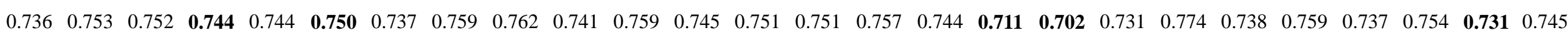
$\begin{array}{llllllllllllllllllllllllllllll}0.747 & 0.759 & 0.763 & 0.754 & \mathbf{0 . 7 4 0} & 0.753 & \mathbf{0 . 7 2 0} & \mathbf{0 . 7 4 1} & 0.756 & \mathbf{0 . 7 3 3} & 0.771 & \mathbf{0 . 7 2 8} & \mathbf{0 . 7 4 8} & \mathbf{0 . 7 3 1} & 0.754 & 0.752 & 0.720 & 0.716 & 0.734 & 0.757 & 0.749 & 0.760 & 0.763 & 0.755 & 0.747 & 0.746\end{array}$ $\begin{array}{llllllllllllllllllllllllllllll}0.752 & 0.760 & 0.756 & 0.758 & 0.744 & 0.759 & 0.751 & 0.745 & 0.752 & 0.770 & 0.757 & 0.756 & 0.764 & 0.756 & 0.751 & 0.746 & 0.750 & 0.752 & 0.746 & 0.765 & 0.759 & 0.756 & 0.752 & 0.757 & 0.747 & 0.755\end{array}$ $\begin{array}{llllllllllllllllllllllllllllll}0.750 & 0.751 & 0.752 & 0.745 & 0.757 & 0.751 & 0.754 & 0.757 & 0.753 & 0.766 & 0.748 & 0.738 & 0.757 & 0.757 & 0.768 & 0.755 & 0.751 & 0.757 & 0.750 & 0.745 & 0.755 & \mathbf{0 . 7 4 3} & 0.748 & 0.772 & 0.750 & 0.753\end{array}$ $\begin{array}{llllllllllllllllllllllllllll}0.735 & 0.754 & \mathbf{0 . 7 3 0} & 0.750 & 0.758 & 0.761 & 0.742 & 0.750 & \mathbf{0 . 7 4 6} & \mathbf{0 . 7 3 3} & \mathbf{0 . 7 4 1} & 0.762 & 0.756 & 0.749 & \mathbf{0 . 7 3 4} & 0.742 & 0.752 & 0.713 & \mathbf{0 . 7 1 9} & \mathbf{0 . 7 4 4} & 0.747 & 0.754 & 0.737 & 0.754 & 0.752 & 0.745\end{array}$ $\begin{array}{llllllllllllllllllllllllll}\mathbf{0 . 7 2 7} & \mathbf{0 . 7 4 5} & 0.756 & \mathbf{0 . 7 4 4} & 0.760 & 0.762 & 0.746 & 0.759 & 0.747 & 0.740 & 0.749 & 0.740 & 0.755 & 0.738 & 0.743 & \mathbf{0 . 7 3 9} & 0.738 & 0.723 & 0.727 & 0.746 & \mathbf{0 . 7 2 5} & 0.758 & \mathbf{0 . 7 2 3} & \mathbf{0 . 7 4 6} & 0.756 & \mathbf{0 . 7 4 4}\end{array}$ $\underline{h=8}$

VAR(1)

VAR(2)

PVAR

TVP( $(\lambda)$-PVAR

$\operatorname{TVP}(\kappa)$-PVAR

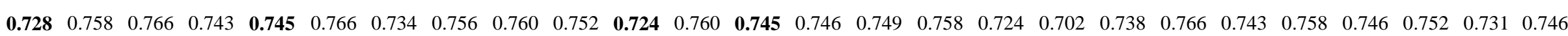
$\begin{array}{llllllllllllllllllllllllllll}0.734 & \mathbf{0 . 7 4 3} & 0.751 & 0.751 & 0.755 & 0.759 & \mathbf{0 . 7 1 5} & 0.753 & 0.755 & 0.745 & 0.750 & 0.750 & 0.749 & 0.760 & 0.748 & 0.761 & \mathbf{0 . 7 1 2} & \mathbf{0 . 7 0 1} & 0.748 & 0.757 & 0.749 & 0.756 & 0.739 & 0.773 & 0.741 & 0.746\end{array}$ $\begin{array}{llllllllllllllllllllllllllllll}0.748 & 0.760 & 0.757 & 0.759 & 0.751 & 0.759 & 0.760 & 0.758 & 0.757 & 0.757 & 0.730 & \mathbf{0 . 7 4 7} & 0.754 & 0.750 & 0.748 & \mathbf{0 . 7 4 5} & 0.752 & 0.749 & 0.741 & \mathbf{0 . 7 4 5} & 0.752 & \mathbf{0 . 7 5 1} & 0.751 & \mathbf{0 . 7 4 2} & 0.752 & 0.751\end{array}$ $\begin{array}{lllllllllllllllllllllllllllll}0.757 & 0.750 & 0.761 & \mathbf{0 . 7 4 2} & 0.748 & \mathbf{0 . 7 4 7} & 0.751 & 0.738 & 0.755 & 0.751 & 0.748 & 0.753 & 0.759 & 0.755 & 0.738 & 0.756 & 0.765 & 0.762 & 0.746 & 0.750 & 0.746 & 0.752 & 0.769 & 0.765 & 0.743 & 0.752\end{array}$ $\begin{array}{lllllllllllllllllllllllllllll}0.737 & 0.744 & \mathbf{0 . 7 3 7} & 0.768 & 0.761 & 0.754 & 0.739 & \mathbf{0 . 7 3 6} & 0.744 & 0.736 & 0.743 & 0.767 & 0.756 & 0.749 & \mathbf{0 . 7 3 2} & 0.747 & 0.742 & 0.723 & 0.718 & 0.755 & 0.739 & 0.763 & 0.741 & 0.751 & \mathbf{0 . 7 3 1} & 0.745\end{array}$ $\begin{array}{llllllllllllllllllllllllllllll}0.738 & 0.756 & 0.740 & 0.755 & 0.766 & 0.763 & 0.733 & 0.755 & \mathbf{0 . 7 4 0} & \mathbf{0 . 7 2 7} & 0.743 & \mathbf{0 . 7 4 7} & 0.748 & \mathbf{0 . 7 4 4} & 0.745 & 0.750 & 0.734 & 0.707 & \mathbf{0 . 7 1 3} & 0.747 & \mathbf{0 . 7 3 6} & 0.752 & \mathbf{0 . 7 3 1} & 0.751 & 0.768 & \mathbf{0 . 7 4 4}\end{array}$ 